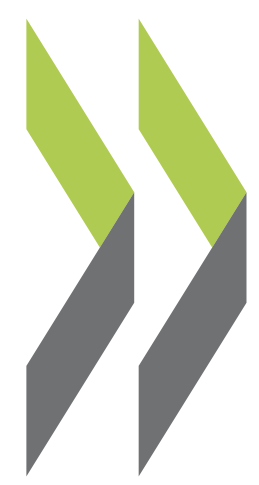

OECD Economics Department Working Papers No. 464

Assessing the Robustness of Demographic Projections Frédéric Gonand in OECD Countries 
Organisation de Coopération et de Développement Economiques

Organisation for Economic Co-operation and Development

07-Dec-2005

ECONOMICS DEPARTMENT

English - Or. English

ASSESSING THE ROBUSTNESS OF DEMOGRAPHIC PROJECTIONS IN OECD COUNTRIES

ECONOMICS DEPARTMENT WORKING PAPERS No. 464

By Frédéric Gonand

All Economics Department Working Papers are available through OECD's Internet Web site at www.oecd.org/eco

JT00195661

Document complet disponible sur OLIS dans son format d'origine

Complete document available on OLIS in its original format 


\section{ABSTRACT/RESUMÉ}

\section{Assessing the robustness of demographic projections in OECD countries}

This paper aims at assessing the robustness of demographic projections to different assumptions on mortality, fertility and migration. It builds on a small-scale simulation model for 23 OECD countries, which reproduces closely national projections under similar demographic assumptions. Up to 2020, projections are relatively robust to alternative hypothesis. However, uncertainty about future longevity gains and fertility rates account for a large range of results for dependency ratios by 2050. Eventually, a long lasting surge in fertility may not be enough to fully offset the impact on dependency ratio of increases in longevity in line with past trends (i.e., around two years every decade).

JEL Classification: J10; J11

Key words: demographic simulations; dependency ratio; longevity

******

\section{Sensibilité des projections démographiques dans les pays de l'OCDE: une évaluation}

Ce document évalue la sensibilité des projections démographiques à différentes hypothèses de mortalité, de natalité et d'immigration. Un modèle simplifié de simulation démographique est construit pour 23 pays de l'OCDE qui permet de reproduire fidèlement les projections des Etats membres à hypothèses identiques. A l'horizon 2020, les projections démographiques seraient assez robustes à leurs hypothèses. A l'horizon 2050, la difficulté à prévoir les évolutions futures de l'espérance de vie et de la natalité introduit une incertitude importante quant au niveau du ratio de dépendance. Enfin, l'effet sur le ratio de dépendance lié à un redressement durable du taux de fertilité ne compenserait pas l'impact d'une poursuite des gains d'espérance de vie selon leur rythme passé (i.e., de deux années par décade).

Classification JEL : J10 ; J11

Mots clés : simulations démographiques ; ratio de dépendance ; espérance de vie 


\section{TABLE OF CONTENTS}

\section{ASSESSING THE ROBUSTNESS OF DEMOGRAPHIC PROJECTIONS IN OECD COUNTRIES ........ 4}

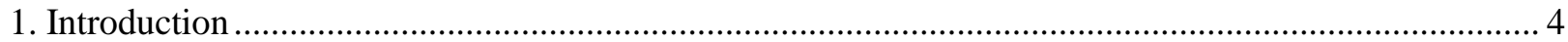

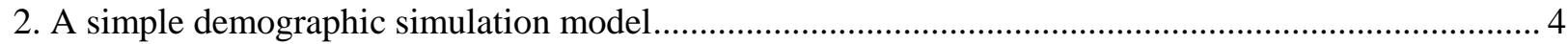

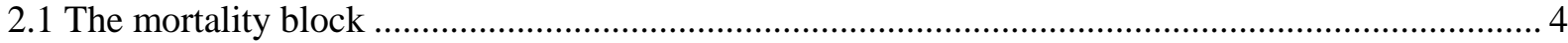

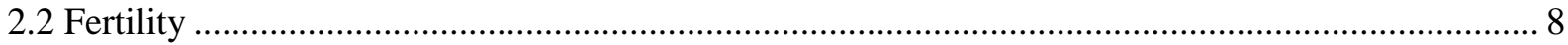

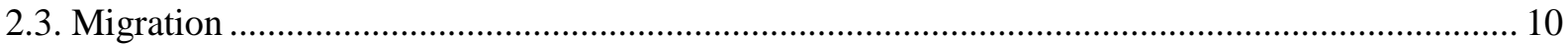

2.4 Comparing simulations with national projections at unchanged demographic assumptions........... 10

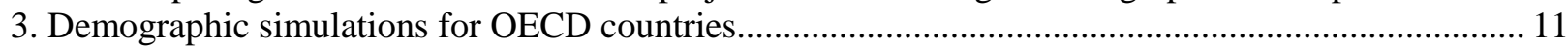

3.1 Impact on the dependency ratio of different future longevity gains ........................................... 11

3.2 Impact on the dependency ratio of different future mortality rates at old age ............................... 11

3.3 Impact on the dependency ratio of different future fertility rates................................................. 12

3.4 Impact on the dependency ratio of different future net migration flows ...................................... 12

4. Conclusion: cumulative impacts of different demographic assumptions ............................................ 12

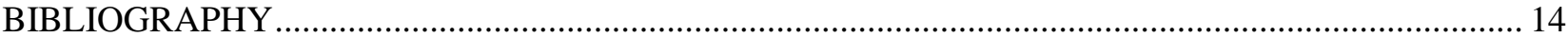




\title{
ASSESSING THE ROBUSTNESS OF DEMOGRAPHIC PROJECTIONS IN OECD COUNTRIES
}

\author{
Frédéric Gonand ${ }^{1}$
}

\section{Introduction}

1. Ageing populations reflect the decrease in fertility rates from baby-boom levels and the steady increase in longevity. Whereas this trend is well documented, projections for the next decades remain surrounded by uncertainty. This paper assesses the robustness of demographic projections to different assumptions about mortality, fertility and migration in 23 OECD countries. It then derives upper- and lower bounds for the dependency ratios up to 2050 .

2. The analysis builds on a small-scale demographic simulation model. Though simple, this model reproduces closely national projections when the same mortality, fertility and migration assumptions are applied. It then allows for analysing the sensitivity of projections to alternative demographic assumptions. The dependency ratio associated with these simulations is defined as (population over 65/population between 15 and 64), which is the relevant definition for the purpose of economic analysis.

3. The paper begins with a presentation of the demographic simulation model used to reproduce closely national projections (Section 2). It then turns to the results of the simulations for 23 OECD countries (Section 3). Section 4 concludes.

\section{A simple demographic simulation model}

4. This demographic model generates long-term demographic simulations based on a limited set of 7 parameters: life-expectancy for women, life-expectancy for men, infant mortality, net migration flows, fertility rate, average age of mothers, and a parameter to take account of mortality at very old age. Using these data, the model projects total population by age-group from 2000 to 2050 (and beyond if needed).

\subsection{The mortality block}

5. The "mortality block" of the model computes surviving populations over time in each cohort given a number of initial births. It uses one assumption about future average life expectancy to derive death rates by sex and 5-years age groups. Defining mortality profiles beyond the age of 85 is more complex and requires a specific methodology. Once all the death rates for every 5-years age group are defined, projecting future surviving population for cohorts currently alive becomes straightforward.

1. OECD Economics Department, 2 rue André Pascal, 75775 Paris Cedex 16, France. I would like to thank Giuseppe Nicoletti, Joaquim Oliveira Martins and Anna-Cristina d'Addio-Devaux for useful comments. Thanks also go to Irene Sinha for secretarial support. 


\section{Deriving death rates up to 84 years}

6. Death rates measure the probability of dying during a given period. As a first step, the model computes death rates between two birthdays. This is done by using Lederman's tables (1969) as updated by Léridon (1996) and slightly modified in this paper. The second step involves transforming these birthdayto-birthday death rates into date-to-date death rates. The latter measure the probability of dying between Jan $1^{\text {st }}$ of year $\mathrm{N}$ and five years later.

7. In what follows, $i$ refers to a 5-years age-group. For example, $i=0$ stands for the age-group of individuals aged between 0 and 4, $i=1$ for the age-group of individuals aged between 5 and 9 , and so on. Index $t$ refers to a 5-years period. For example, $t=0$ stands for period 2000-2005, $t=1$ for period 20052010 , and so on.

\section{[Figure 1: Structure of a cohort born between 2000 and 2004]}

8. Lederman (1969) estimates death rates for each sex and age-group using only one input, i.e., average life expectancy at birth. Using a multinational database, he regresses the probability for someone celebrating his/her $5(\mathrm{i})^{\text {th }}$ birthday in $t$ of dying before his/her $5(\mathrm{i}+1)^{\text {th }}$ birthday on life expectancy. For example, Lederman estimates the probability for an individual who belongs to the 5-9 years-old group in 2005-2009 of dying before entering the 10-14 years-old group between 2010 and 2014².

9. For individuals aged 5 to 84 ( $i=1$ to $i=16)$, death rates are computed using Lederman's following formula and parameters:

$$
\begin{aligned}
& Q L M(i, t)=\exp \left[2.30258 . a(i)+b(i) \ln \left(115-\varepsilon\left(E S P M_{t}\right)\right)\right] \\
& Q L W(i, t)=\exp \left[2.30258 . c(i)+d(i) \ln \left(115-\varepsilon\left(E S P W_{t}\right)\right)\right]
\end{aligned}
$$

where $Q L M(i, t)$ stands for the probability for a man celebrating its 5.(i $)^{\text {th }}$ birthday during period $t$ of dying before celebrating its $5 .(\mathrm{i}+1)^{\text {th }}$ birthday; $Q L W(i, t)$ refers to the same probability of dying for women; ESPM $M_{t}$ and $E S P W_{t}$ stand respectively for the average life-expectancy at birth in $t$ for men and women. Parameters $a(i), b(i), c(i)$ and $d(i)$ are drawn from Ledermann's estimated death rates table; 115 years is assumed to be the maximum limit of human life; and the expressions $\varepsilon\left(E S P M_{t}\right)$ and $\varepsilon\left(E S P W_{t}\right)$ refer to an increasing function of average life expectancy at birth. In Lederman's original computations, the function $\varepsilon$ is the identity function: $\varepsilon\left(E S P_{t}\right)=E S P_{t}$ where $E S P_{t}$ refers to a given value of life-expectancy. The higher the longevity, the lower the probability of death at each age.

10. Lederman's methodology for modelling mortality has many advantages. It is very well suited for a simulation exercise with few demographic data at hand. Yet this method suffers also from serious drawbacks. Estimated parameters $a(i), b(i), c(i)$ and $d(i)$ in the above formulas were computed during the 60's using 154 mortality tables from 48 countries. In other words, they reflect mortality half a century ago, including in countries then poorly developed. Applying Lederman's parameters would thus grossly overestimate mortality for developed countries in the $21^{\text {st }}$ century.

11. To make up for these drawbacks, Léridon (1996) and Léridon and Toulemon (1997) suggest adjusting Lederman's formula using the following quadratic function $\varepsilon\left(E S P_{t}\right)=0.009^{*}\left(E S P_{t}\right)^{2}+0.11^{*} E S P_{t}+17$.

2. In this case, the 10th birthday lies between 2010 and 2014 depending on the date of birth between 2000 and 2004. 
The obtained death rates are much lower at any age than Lederman's (1969). Yet the estimation method of the two coefficients in the polynomial is not detailed by the authors. Computed ten years ago, they still overestimate death rates. Thus, using the Leridon-adjusted death rates in the demographic simulation model under the same assumptions as in national projections yields a dependency ratio ${ }^{3}$ much lower than the projected official one. ${ }^{4}$

12. In this context, we used Léridon's polynomial adjustment but slightly modified the value of its second-order coefficient so as to get a dependency ratio that is close to the official one. We thus calibrated the model on 0.0115 for men and 0.01 for women (instead of 0.009 in Léridon). ${ }^{5}$ In all countries, this adjustment yields demographic projections well in line with official ones at unchanged assumptions.

13. Age-group 0-4 requires a somewhat specific treatment. For these individuals $(i=0)$, the computation of the probability of dying before the $5^{\text {th }}$ birthday takes into account the infant mortality $\left(\right.$ noted $\inf _{t}$ ):

$$
\begin{aligned}
& \operatorname{QLM}(0, t)=\frac{2 * \inf _{t}}{2+\inf _{t}}\left(\exp \left[2.30258 . a(1)+b(1) \ln \left(115-\varepsilon\left(E S P M_{t}\right)\right)\right]\right) \\
& Q L W(0, t)=\frac{2 * \inf _{t}}{2+\inf _{t}}\left(\exp \left[2.30258 . c(1)+d(1) \ln \left(115-\varepsilon\left(E S P W_{t}\right)\right)\right]\right)
\end{aligned}
$$

14. These Lederman death rates do not correspond exactly to what is needed in the model to match national projections. In Figure 2, Lederman's $\operatorname{QLM}(2,2)$ corresponds to the probability for a man/woman celebrating his/her $10^{\text {th }}$ birthday between 2010 and 2014 of dying before celebrating his/her $15^{\text {th }}$ birthday (occurring between 2015 and 2019 depending on the precise date of birth between 2000 and 2004). Yet the model requires computing the probability for an individual born between 2000 and 2004and alive on January $1^{\text {st }}, 2010$ of dying before January $1^{\text {st }}, 2015 .^{6}$ Fortunately the date-to-date death rates can easily be derived from Lederman's death rates.

15. For individuals aged 10 to 84, Lederman's death rates are transformed into date-to-date death rates using the formula:

$$
\begin{array}{ll}
Q M(i, t)=\frac{Q L M(i-1, t-1)}{2-Q L M(i-1, t-1)}+\frac{Q L M(i, t)}{2}-\frac{Q L M(i-1, t-1) \cdot Q L M(i, t)}{4} & (i \in[2 ; 17]) \\
Q W(i, t)=\frac{Q L W(i-1, t-1)}{2-Q L W(i-1, t-1)}+\frac{Q L W(i, t)}{2}-\frac{Q L W(i-1, t-1) \cdot Q L W(i, t)}{4} \quad(i \in[2 ; 17])
\end{array}
$$

where $Q M(i, t)$ and $Q W(i, t)$ stand for the probability for a man/woman alive at the beginning of period $t$ of dying before the beginning of period $t+1$.

3. The dependency ratio is computed here as (population over 65/population between 15 and 64).

4. On French data, it also overestimates death rates by age-groups as compared to Vallin and Meslé (2001).

5. The parameter for men is slightly higher than for women in order to take into account the literature about the gradually shrinking difference of longevity between sexes.

6. This is because national projections for 5-years periods are computed at January, 1st of each first year of each period. See for instance Brutel C. (2001), Projections de population à l'horizon 2050, INSEE Première, 762. 
16. Figure 2 illustrates the intuition lying behind these expressions. They rely on the assumption that births are homogenously distributed over each $t$. Thus a 5-years age-group can be represented by its average individual born in the middle of the period of birth of the age-group. They also assume deaths to be homogenously distributed between the $5 . i^{\text {th }}$ and $5 .(i+1)^{\text {th }}$ birthdays for individuals born the same day.

\section{[Figure 2: From Lederman's death rates to date-to-date death rates: an example]}

17. This method of computing date-to-date death ratios differs slightly from Sleiman (2002) who computes $Q M(i, t)$ as the average between $Q L M(i-1, t-1)$ and $Q L M(i, t)$. Sleiman's formula tends to the more precise estimates proposed in this paper for small values of Lederman's death rates. The numerical example given in Figure 2 shows $Q M(3,3)$ to be close to - yet different from - the average of $Q L M(2,2)$ and $\operatorname{QLM}(3,3)(15.11 \%$ compared to $15 \%$, respectively).

18. For individuals aged 0 to 4 , specific calculations are needed. For this age-group, the model requires computing the number of individuals born during period $t$ and still alive on the first day of period $t+1$ (noted $S M_{1, t+1}$ ). It can be showed that the average death rate for someone born during period $t$ up to the first day of period $t+1$ is $0.90625 . \operatorname{LLM}(0, t)$ for men or $0.90625 . Q L W(0, t)$ for women. ${ }^{7}$

19. Consequently, for individuals aged 5 to 9, date-to-date death rates become:

$$
\begin{aligned}
& Q M(1, t)=\frac{0.09375 \cdot Q L M(0, t-1)}{1-0.09375 \cdot Q L M(0, t-1)}+\frac{Q L M(1, t)}{2}-\frac{0.09375 \cdot Q L M(0, t-1) \cdot Q L M(1, t)}{2} \\
& Q W(1, t)=\frac{0.09375 \cdot Q L W(0, t-1)}{1-0.09375 \cdot Q L W(0, t-1)}+\frac{Q L W(1, t)}{2}-\frac{0.09375 \cdot Q L W(0, t-1) \cdot Q L W(1, t)}{2}
\end{aligned}
$$

\section{Deriving death rates above 85}

20. Estimating and projecting death rates at higher ages has become an increasingly debated and still unsettled issue among demographers over the past decade (Thatcher, Kannisto and Vaupel, 1998). Apart from empirical and data availability problems (Meslé and Vallin, 2000), the debate focuses on the statistical law that might best fit with mortality dynamics at very old age.

21. Some degree of consensus seems currently to have been reached on at least two points:

- Biodemographic studies found a remarkable similarity in survival dynamics between humans and laboratory animals. The Gompertz law states that mortality increases exponentially with age (Gavrilov, 2004). Empirically, this law is valid for ages between 35 and 80. The death rates in the demographic simulation model take this into account. For example, Figure 3 (with semi-log scale) shows the death rates computed for the cohort born in 2000.

7. Lederman's method allows for computing the probability for an individual born during period $t$ of dying before its 5 th birthday in $t+1$, which is noted $Q L M(0, t)$. Sleiman (2002) suggests that $85 \%$ of mortality for individuals aged 0-4 is concentrated during the first year of life. Given the assumption of constant birth flows during period $t$ which enables to represent a cohort born in period $t$ by an average individual born in the middle of $t$, the probability for this average individual to die before the first day of period $t+1$ is $0.85 * Q L M(0, t)+(1.5 / 4) * 0.15 * Q L M(0, t)=90.625 \% * Q L M(0, t)$. Sleiman simplifies by retaining $85 \%$ only. 


\section{[Figure 3: Death rates for men and women: an example]}

- Yet, over the past decade, demographic studies increasingly questioned the validity of Gompertz law at higher ages, for which it clearly seems to overstate mortality.

22. Demographic research has tried to refine the Gompertz approach for higher ages, for instance by using logistic models (Thatcher, 1999). The method proposed by Lee and Carter (1992) is widely used but is based on the doubtful assumption of a constant rate of decline in mortality. This hypothesis is challenged by empirical evidence. The consequences are not negligible if projections are made over several decades. ${ }^{8}$

23. Other researchers argued that mortality is likely to level off after some (unspecified) threshold. This would have far-reaching consequences: with death rates stabilizing after a threshold, human longevity would be uncapped and would keep increasing at a rapid rate in the next decades. Such an issue remains very controversial among demographers. The levelling-off argument might underestimate mortality at old age: empirical evidence over the long run shows that survival probability curves have become increasingly rectangular on their right-hand side (Kannisto, 2000) ${ }^{9}$. This suggests at least that mortality keeps increasing at very old age - albeit not exponentially as in the Gompertz law.

24. Given this uncertainty, the methodology adopted in the demographic simulation model remains agnostic. Death rates above 85 are computed as a weighted average of their value according to the Gompertz law and the levelling-off argument. The former provides an upper-bound for mortality and the latter a lower bound. ${ }^{10}$ The value of the weighting parameter is between 0 and 1 and is set at 0.5 unless stated otherwise. ${ }^{11}$ Figure 4 displays different survival probability curves for different values of this parameter. ${ }^{12}$

\section{[Figure 4: Proportion of surviving individuals in a cohort of women/men born in 2000]}

\subsection{Fertility}

25. The "fertility block" of the model computes at any date an age-specific fertility function for a population. This function links the number of births to a population of women ranked by age.

26. Defining the age-specific fertility function $\varphi\left(x_{t}\right)$ requires assumptions about three parameters:

8. This explains why private insurers tend to use the Lee-Carter method only over the short-run (i.e., up to 10 or 15 years in this context).

9. This rectangularisation suggests that human life might have natural limits (around 120 years).

10. The form of the Gompertz function is $Q M(i, t)=\exp (a+b .5 i)$. Parameters a and $\mathrm{b}$ are derived from a 2equations system obtained with $\mathrm{QM}(10, \mathrm{t})$ and $\mathrm{QM}(16, \mathrm{t}+6)$, which values are computed following Lederman and Leridon (see above). The same is done for estimating $Q W(i, t)$.

11. 1 corresponds to a pure Gompertz case, 0 to a pure leveling-off argument. Strictly speaking, the average life-expectancy at birth in the model should be positively related with the hypothesis used for mortality over 85. Yet the magnitude of this impact remains very limited (less than one year of longevity) and is neglected is the model.

12. Strictly speaking, the average life expectancy at birth used in the model should be positively related with the hypothesis used for mortality over 85 . Yet, the magnitude of this impact remains very limited and is neglected in the model. 
- The total fertility rate in period $t\left(T F R_{t}\right)$. This rate measures the average number of children a cohort of women would have during their fertile period (i.e., 15 to 49) assuming that this cohort has the same fertility rates by age as women at the date for which the total fertility rate is computed.

- The average age of women at the date of birth of their children in period $t$, noted $E\left(x_{t}\right)$, where $x_{t}=0$ for women aged 15, $x_{t}=1$ for women aged 16 and so on until women aged 49 .

- The variance of the age of women at the date of birth of their children at a given period $t: \sigma_{x_{t}}^{2}$.

27. To derive the age-specific fertility function from these parameters, we rely on the function tested by Duchêne and Gillet de Stéphano (1974):

$$
\varphi\left(x_{t}\right)=\frac{\operatorname{TFR}_{t} \cdot\left(\frac{E\left(x_{t}\right)}{\sigma_{x_{t}}^{2}}\right)^{\frac{\left(E\left(x_{t}\right)\right)^{2}}{\sigma_{x_{t}}^{2}}} \cdot\left(x_{t}\right)^{\frac{\left(E\left(x_{t}\right)\right)^{2}}{\sigma_{x_{t}}^{2}}-1} \cdot e^{-x_{t} \frac{E\left(x_{t}\right)}{\sigma_{x_{t}}^{2}}}}{\Gamma\left(\frac{\left(E\left(x_{t}\right)\right)^{2}}{\sigma_{x_{t}}^{2}}\right)}
$$

where $\varphi\left(x_{t}\right)$ stands for the number of children for 1000 women aged $x_{t}$ and $\Gamma$ is the gamma function. This formula makes it possible to compute fertility by age using assumptions about future $T F R_{t}$, $E\left(x_{t}\right)$ and $\sigma_{x_{t}}^{2}$.

28. It is much harder to make assumptions about the future variance of the age of mothers $\left(\sigma_{x_{t}}^{2}\right)$ than about future total fertility rates $\left(T F R_{t}\right)$ or even the future average age of mothers $\left(E\left(x_{t}\right)\right)$. Yet Duchêne and Gillet de Stéphano (1974) suggest a rather efficient shortcut for projecting $\sigma_{x_{t}}^{2}$ : the future variance of the age of mothers at the date of birth of their children can be computed as a function of the total fertility rate $\left(T F R_{t}\right)$ using the regression $\left(\sigma_{x_{t}}^{2}\right)_{\text {country }}=\left[1.53749 \ln \left(T F R_{t}\right)+4.37728\right]^{2} .^{13}$

29. The age-specific fertility rates are initially computed for annual $x_{t}$ 's and then averaged so as to yield 5-years age-groups data. Overall the obtained fertility profile seems realistic (Figure 5), event though they tend to underestimate fertility of early ages on French data.

[Figure 5: Theoretical vs. observed distribution of births by age of the mother (France, 1995)]

30. Using this method and knowing the number of women between 15 and 49 at the beginning of the period of projection, one can derive the number of births at this date, ${ }^{14}$ then the number of individuals

13. Duchêne and Gillet de Stéphano (1974) obtain these estimates using demographic data from different countries in the 1960's. Applying their formula to the fertility rates observed in 1995-2000 yields simulated age variances by countries not too far from the observed ones. The impact on the projected dependency ratio of the difference between recently observed and simulated age variances is very small. Thus adjusting Duchêne and Gillet de Stéphano's formula is not necessary. Overall, the results in the model do not depend very much on this parameter.

14. Total births are broken down between boys and girls applying respectively the following proportions (which are very stable over time): 0.512 and 0.488 . 
surviving afterwards by applying death rates to these new cohorts, and eventually the number of future births given the number of surviving women in a cohort and the future age-specific fertility function. Overall this yields a total population projection - without migration flows.

\subsection{Migration}

31. Taking into account international migration flows relies on a purely accounting framework. Modelling immigration is possible but remains very fragile given the uncertainty about future trends in immigration policies among countries.

32. In this context, the model requires only one hypothesis as concerns the average annual net migration flows in every 5 -years period. These net flows are assumed equally distributed by sex. They are distributed by age-group according to the average values across 6 countries for which data were available. ${ }^{15}$ Immigrants are supposed to have the same mortality and fertility rates as nationals.

\subsection{Comparing simulations with national projections at unchanged demographic assumptions}

33. The demographic simulations of the model can be compared with the official ones when the same assumptions are used as concerns mortality, the fertility rate and net migrations flows. Life-expectancy in the model converges linearly to its level as in official projections for $2050 .{ }^{16}$ In the old-age mortality scenario, the value of the weighting parameter mapping mortality at old age is set at 0.5 . It thus corresponds to the median scenario depicted in Figure 4.

34. Overall, the model produces demographic simulations that are close to the official projections under the same assumptions concerning mortality, fertility and migration. ${ }^{17}$ Figure 6 shows that the dependency ratio (population over 65/population between 15 and 64) in the national projections and in the model simulations are very close to the official projections in 23 OECD countries. ${ }^{18}$

[Figure 6: Dependency ratio in the simulation model vs. national projections]

35. A more detailed comparison between national and simulated scenarios - by age-group and by period - also points to relatively small differences. Figure 7 suggests that the model projections are for all dates and age-groups within a few percentage points (at most) from the official projections. ${ }^{19}$

15. More precisely, the average structure by age of net migration flows is based on data for Germany, France, Italy, United Kingdom, Netherlands and Sweden as computed by Sleiman (2002). This structure is : 0-4 years: $8.5 \%, 5-9$ years: $8.0 \%, 10-14$ years: $7.4 \%, 15-19$ years: $17.4 \%, 20-24$ years: $23.2 \%, 25-29$ years: $16.7 \%$, 30-34 years: $10.1 \%, 35-39$ years: $3.5 \%$, 40-44 years: $5.6 \%, 45-49$ years: $3,3 \%$, 50-54 years: $1,0 \%$, 55-59 years: $0.8 \%, 60-64$ years: $-5.5 \%$ (this figure is negative due to a few immigrants going back to their home country after retiring), 65-69 years: $0.3 \%$.

16. If the official assumption about longevity does not go as far as 2050 , longevity is assumed to stabilize after the farthest date available.

17. In all simulations, the average age of mothers is assumed to converge linearly to 30 years in 2050 . This is in line with past trends.

18. Countries where some data were not available or where the simulated dependency ratio was more than $5 \%$ different in 2050 from the official one were not selected in the panel.

19. Differences in the French case for old-age are always less than $10 \%$ and concern a relatively small agegroup. 
[Figure 7: Differences between the structure of the population by age in the simulation model and in national projections]

\section{Demographic simulations for OECD countries}

36. Using the demographic simulation model illustrated above, this section investigates the sensitivity of projected dependency ratios to changes in the demographic assumptions underlying national projections. The dependency ratio is defined as (population over 65/population between 15 and 64).

\subsection{Impact on the dependency ratio of different future longevity gains}

37. As argued in Oliveira Martins et al.. (2005), there is considerable debate about future longevity gains among OECD countries. National projections assume on average that these gains may decelerate from their current long-run trend of more than two years per decade to 1.3 year per decade. For the time being, current data do not show any sign of this deceleration. We simulate three scenarios: no longevity gains from 2000 onwards, gains of one year per decade and gains of two years per decade. All others demographic assumptions are as in the national projections.

\section{[Figure 8: Dependency ratio and future longevity gains]}

38. Up to 2030, alternative assumptions concerning future longevity gains would not impact significantly the dynamics of the dependency ratio. Since mortality remains relatively low below 70 years, most baby-boomers will still be alive in the 2020's whether life-expectancy increases or not.

39. However, from 2030 on, the magnitude of longevity gains would have a significant and, in some countries, dramatic impact on the dependency ratio. Higher longevity gains would accelerate the upward trend of the dependency ratio associated with the post-baby boom decline in fertility. The stronger this baby-boom effect, the more longevity gains may bolster the ageing process. For countries where national projections embody a dependency ratio of $60 \%$ or more in 2050 (Japan, Italy, Spain, Korea, Poland), different assumptions concerning future longevity gains translate into a sensitivity range of around 15 percentage points around the postulated dependency ratio in 2050 . This range peaks at 20 percentage points in the case of Japan. For countries where national authorities project a dependency ratio of 45-50\% in 2050 (Germany, Austria, Belgium, France, Finland, Portugal), the sensitivity bound is still about 10 percentage points. For countries ageing less rapidly (Netherlands, Denmark, Great Britain, Norway, New Zealand, Canada, Iceland), the interval is at most 10 percentage points. For Turkey and Mexico, which do not face a strong ageing process, it is negligible.

\subsection{Impact on the dependency ratio of different future mortality rates at old age}

40. As argued in Section 2., the issue of mortality above 85 remains largely unsettled today. We run three scenarios as depicted in Figure 4, where the value of the weighting parameter mapping mortality at old age between the Gompertz law and the levelling-off argument takes the value 0, 0.5 or 1 respectively. In the first case, mortality levels off after 85. In the third case, the Gompertz law keeps applying after 85.

\section{[Figure 9: Dependency ratio and future mortality at old age]}

41. In most countries, the uncertainty concerning mortality at old age will probably not have strong consequences for the dependency ratio in the next decades. Only one or two percentage points in 2050 are at stake on average. Yet in the Japanese case, very low mortality at old age could still increase the dependency ratio by up to $5 \%$. 


\subsection{Impact on the dependency ratio of different future fertility rates}

42. Fertility rates are notoriously hard to forecast. It remains unclear whether they follow a cyclical pattern or are subject to sudden changes. Currently, most OECD countries experience a fertility rate that is too low for stabilizing their population in the long-run (i.e., less than 2.1). We attempt to take account of these features by running two simulations. In the first, the fertility rate remains constant from $2000 \mathrm{on}$. In the second scenario, it converges linearly to 2.1 in 2025 and remains constant thereafter.

\section{[Figure 10: Dependency ratio and fertility rate]}

43. Not surprisingly, a recovery of the fertility rate in countries where it is currently low would significantly alleviate upward pressures on their dependency ratio. This effect would not materialize before 2030. Yet, the sensitivity range for the dependency ratio in 2050 would be between 5 and 15 percentage points. In most countries, this range is close to the one obtained in the simulations with different longevity gains assumptions.

\subsection{Impact on the dependency ratio of different future net migration flows}

44. Migration flows are essentially determined by policies. Thus, they are hard to forecast in the long-run. However, national projections provide some indications in this matter. We run two simulations, the first one relying on official assumptions about migration, the second assuming net migration flows twice as large as official ones in countries where there is net immigration throughout the projection period. $^{20}$

\section{[Figure 11: Dependency ratio and net migration flows]}

45. Results suggest that a sharp increase in net migration flows over the whole period would not have a significant effect in several countries (e.g., France, Japan). In these cases, the associated sensitivity range for the dependency ratio would amount to five percentage points on average in 2050. The range would be somewhat higher in countries with high immigration (in relative terms) as Germany, Austria, Canada, Italy, Spain and United Kingdom. In these countries, the effect on the dependency ratio of a sharp increase in net migration flows is comparable with the one observed in the simulations involving higher fertility. This effect of higher migration flows would materialize more rapidly than in the other simulations.

\section{Conclusion: cumulative impacts of different demographic assumptions}

46. Uncertainty about future demographic phenomena flows mainly from the unpredictability of future longevity gains and fertility dynamics. Uncertainty about mortality at old age and, to a lesser extent, net migration flows, might play a smaller role. It is interesting, however, to investigate the cumulative effect on projected dependency ratios of different demographic assumptions.

47. Bearing in mind the illustrative nature of simulation exercises, the overall sensitivity of the projected dependency ratios to demographic assumptions is assessed by running two alternative simulations for each country. In the lower-bound scenario, we assume no longevity gains, a fertility rate converging to 2.1 in 2025 , the validity of the Gompertz law and high migration flows. The upper-bound scenario assumes longevity gains of 2 years per decade, a constant fertility rate from 2000 on, levelling-off mortality after 85 and national migration assumptions.

20. Net migration flows are negative in national projections for Korea, Mexico and Turkey, and zero in Poland. No migration scenario is run for these countries. 
[Figure 12: Overall sensitivity range: upper- and lower-bound scenarios]

48. The dependency ratio in the lower- and upper- bound scenarios displays very different patterns in all countries, reflecting cumulative and polar - yet far from unrealistic - assumptions. On average, the difference between the dependency ratios in 2050 in both scenarios is around 20 percentage points. In countries ageing rapidly, the difference appears still bigger (up to 40 percentage points in Japan and Italy). By contrast, the United States will probably not experience any strong ageing process even in the upperbound scenario.

49. These lower- and upper- bound scenarios are useful to assess the widest possible range for future dependency ratios. In the lower-bound scenario, fertility picks up and longevity does not increase, whereas longevity increases and fertility remains relatively low in the lower-bound scenario. For each country, we then run a high longevity and fertility scenario and a low longevity and fertility scenario. ${ }^{21}$ In the former, we assume longevity gains of two years per decade, levelling-off mortality after 85 and a fertility rate converging to 2.1 in 2025 . In the latter, we assume no longevity gains, the validity of the Gompertz law and a constant fertility rate from 2000 on. $^{22}$

\section{[Figure 13: High longevity and fertility vs. low longevity and fertility scenarios]}

50. As suggested in Figure 13, the dependency ratio in the "high longevity and fertility" scenario is higher than in the "low longevity and fertility" scenario in all countries. The difference between both scenarios lies between 5 and 10 percentage points in $2050 .^{23}$ In 2025 , it is twice smaller on average. This result suggests that a surge in fertility may not be enough to fully offset the effect on dependency ratio of longevity increases in line with past trends (i.e., around two years every decade).

21. In both scenarios, net migration flows correspond to national assumptions.

22. For countries where the fertility rate is above 2.1 in 2000 , national projections assume this rate to decline below 2.1 in the future. Thus the "high fertility" for these countries remains the convergence to 2.1 in 2025 and the "low fertility" assumption corresponds to national projections. This only applies to Mexico and Turkey.

23. Exceptions are Korea and Poland, where the difference between both scenarios in 2050 is close to zero. 


\section{BIBLIOGRAPHY}

Duchêne, J., S. Gillet de Stéphano (1974), «Ajustement analytique des courbes de fécondité générale », Population et famille, 32.

Gavrilov, L. and N.S. Gavrilova (1991), The Biology of Life Span: A Quantitative Approach, Harwood Academic Publishers.

Gavrilov, L. (2004), "Biodemography of Human Longevity", keynote lecture at the International Conference on Longevity, Sydney, Australia, March 5-7.

Greenwood, M. and J. Irwin (1939), “The Biostatistics of Senility”, Human Biology, (11).

Kannisto, V. (2000), "Measuring the Compression of Mortality”, Demographic Research, 3.

Lederman, S. (1969), "Nouvelles-tables-types de mortalité", Travaux et documents de l'Institut National des Etudes Démographiques, cahier 53.

Lee, R. and L. Carter (1992), "Modelling and Forecasting US Mortality", Journal of the American statistical association, 87.

Léridon, H. (1996), “Pyramides animées”, Institut National des Etudes Démographiques.

Meslé, F. and J. Vallin (2000), «Comment améliorer la précision des tables de mortalité aux grands âges ? Le cas de la France », Population.

Oliveira Martins, J., F. Gonand, P. Antolin, C. de la Maisonneuve and K. Yoo (2005), "The Impact of Ageing on Demand, Factor Markets and Growth", OECD Economics Department Working Papers, No.420.

Sleiman, R. (2002), "Projections démographiques de quelques pays de l'Union Européenne”, Cahier de travail du CEPII, 13.

Thatcher, A.R. (1999), "The Long-Term Pattern of Adult Mortality and the Highest Attained Age", Journal of the Royal Statistical Society, 162.

Thatcher, A.R., V. Kannisto, J.W. Vaupel (1998), The Force of Mortality at Ages 80 to 120, Monographs on population aging 5, Odense University Press.

Vallin, J. et F. Meslé (2001), "Tables de mortalité françaises pour les XIXème et XXème siècle et projections pour le XXIème siècle", Institut National des Etudes Démographiques - Données statistiques, (4). 
ECO/WKP(2005)51

Figure 1 : Structure of a cohort born between 2000 and 2004

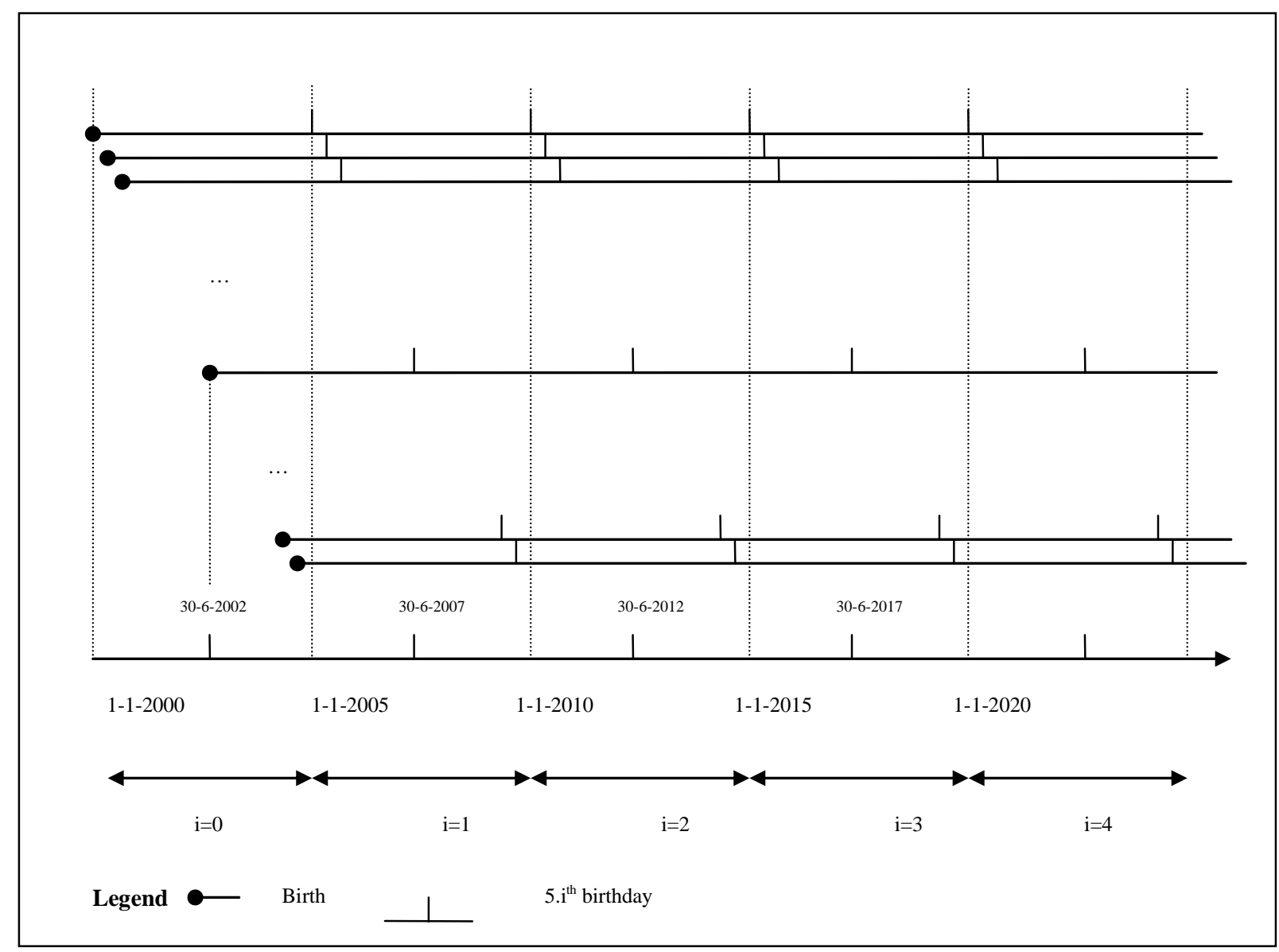


Figure 2 : From Lederman's death rates to date-to-date death rates: an example

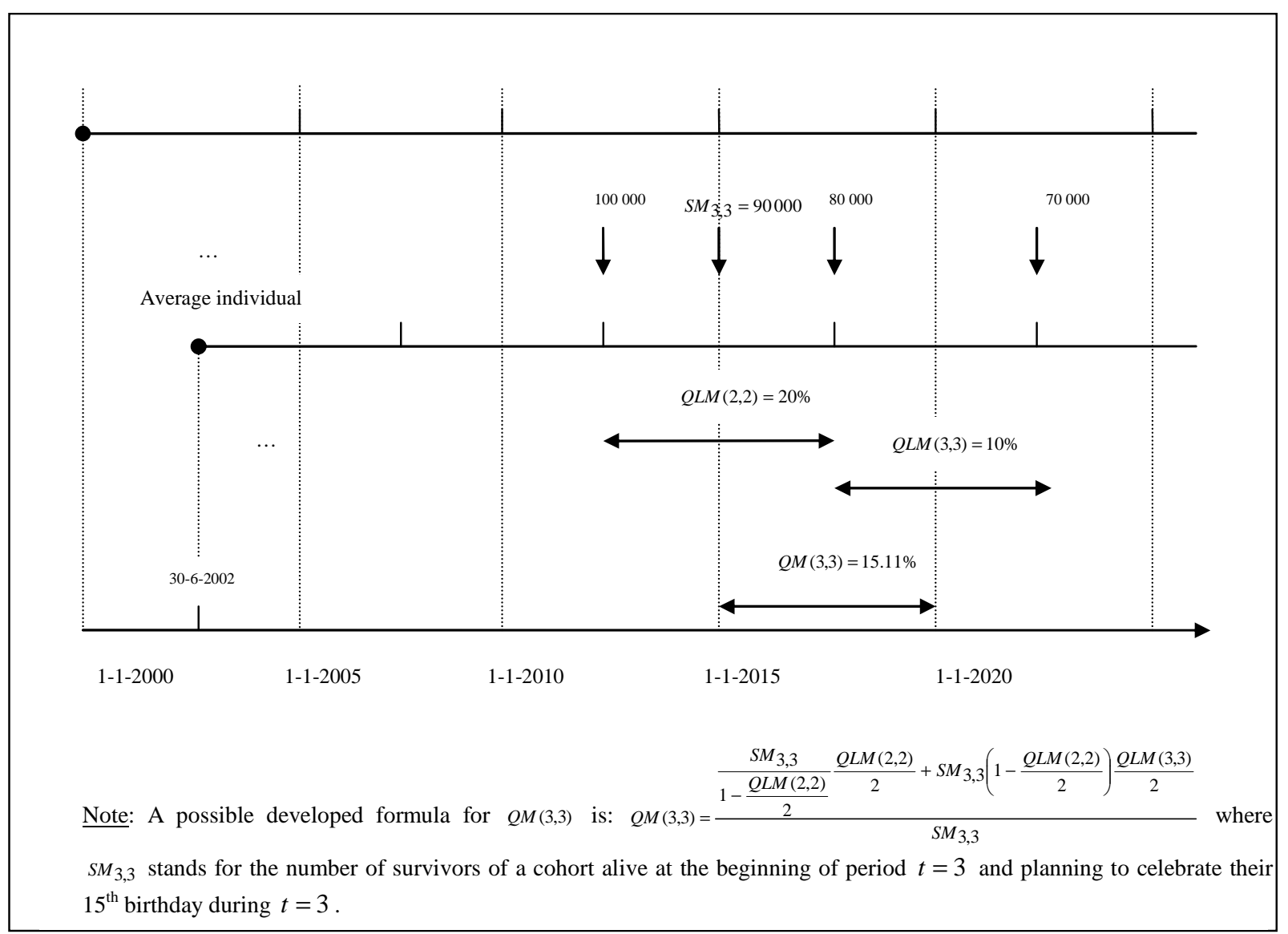


ECO/WKP(2005)51

Figure 3 : Death rates for men and women : an example

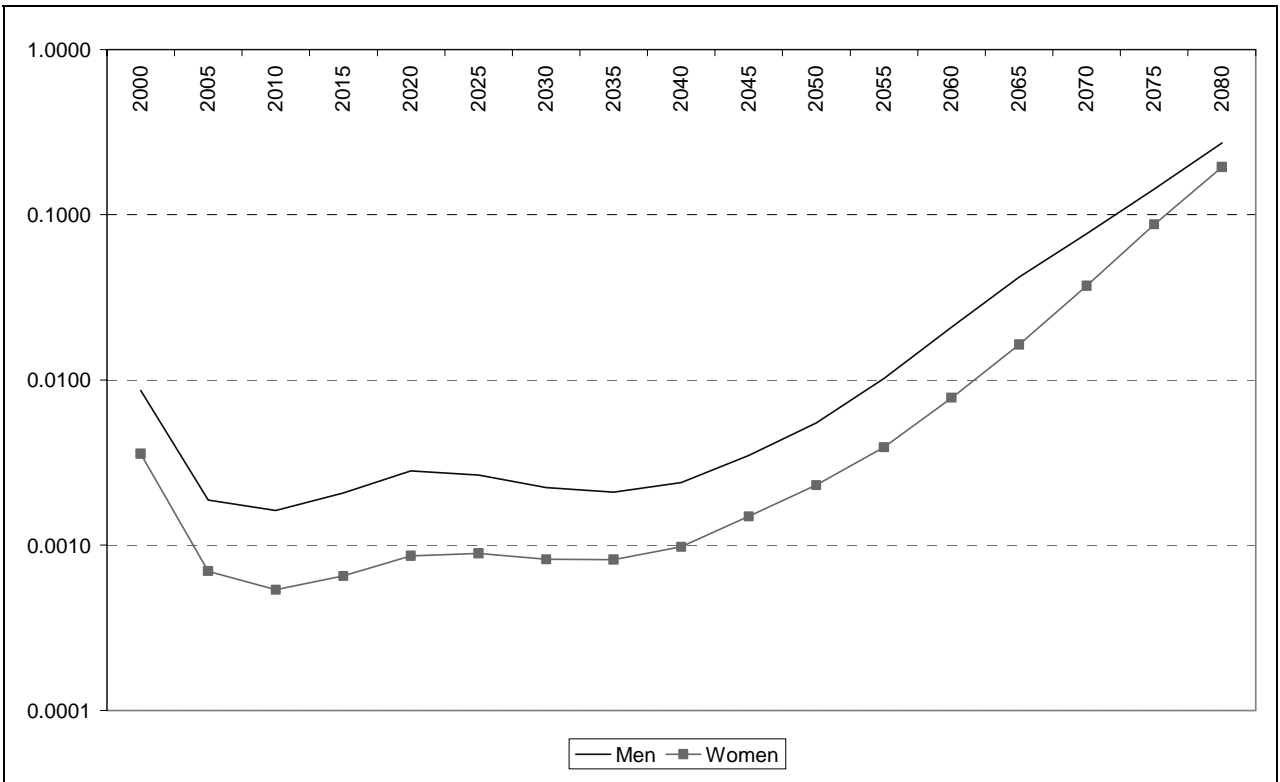


Figure 4 : Proportion of surviving individuals in a cohort of women/men born in 2000
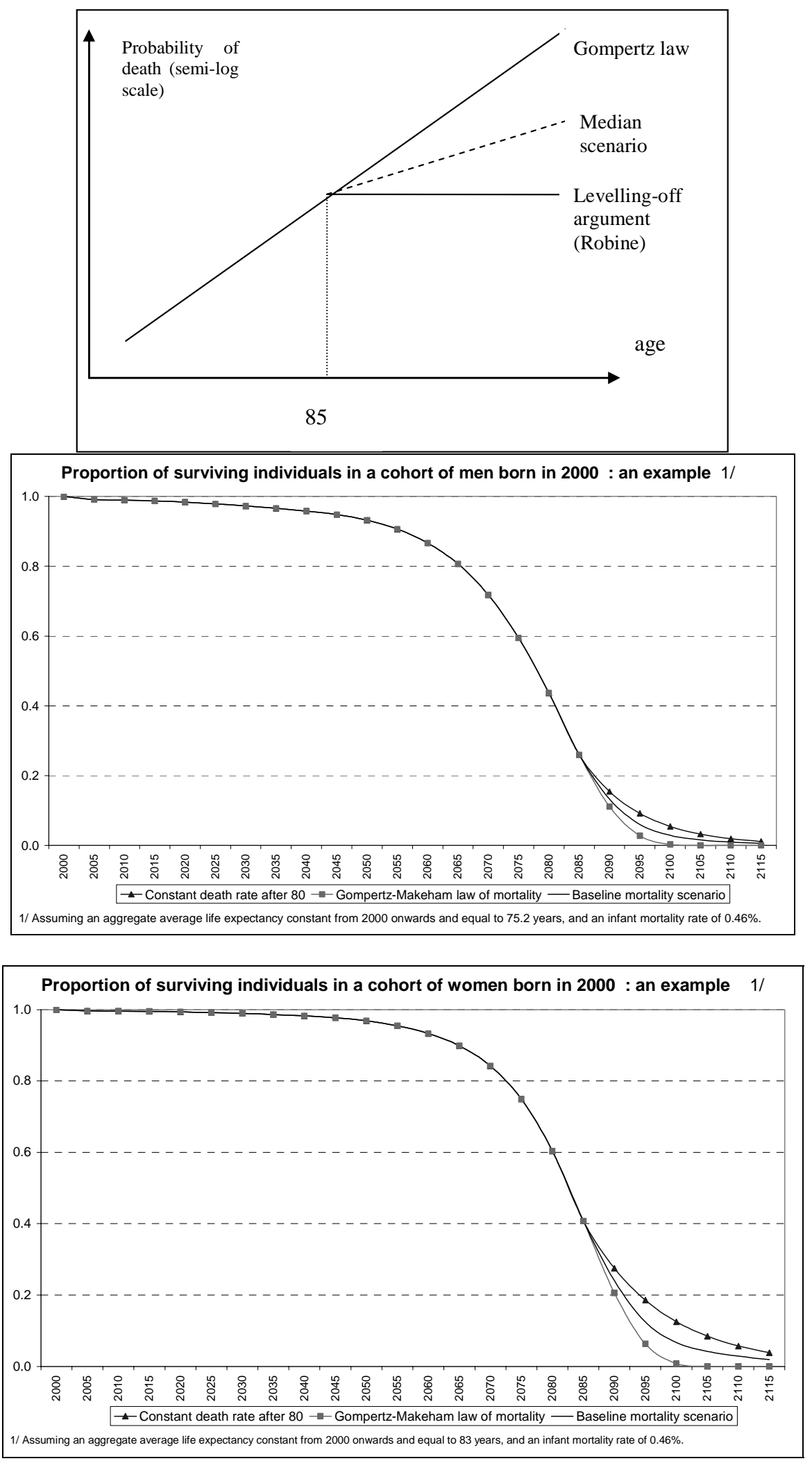
ECO/WKP(2005)51

Figure 5 : Theoretical vs observed distribution of births by age of the mother (France, 1995))

Theoretical distribution of birth in 1995 (FRA)

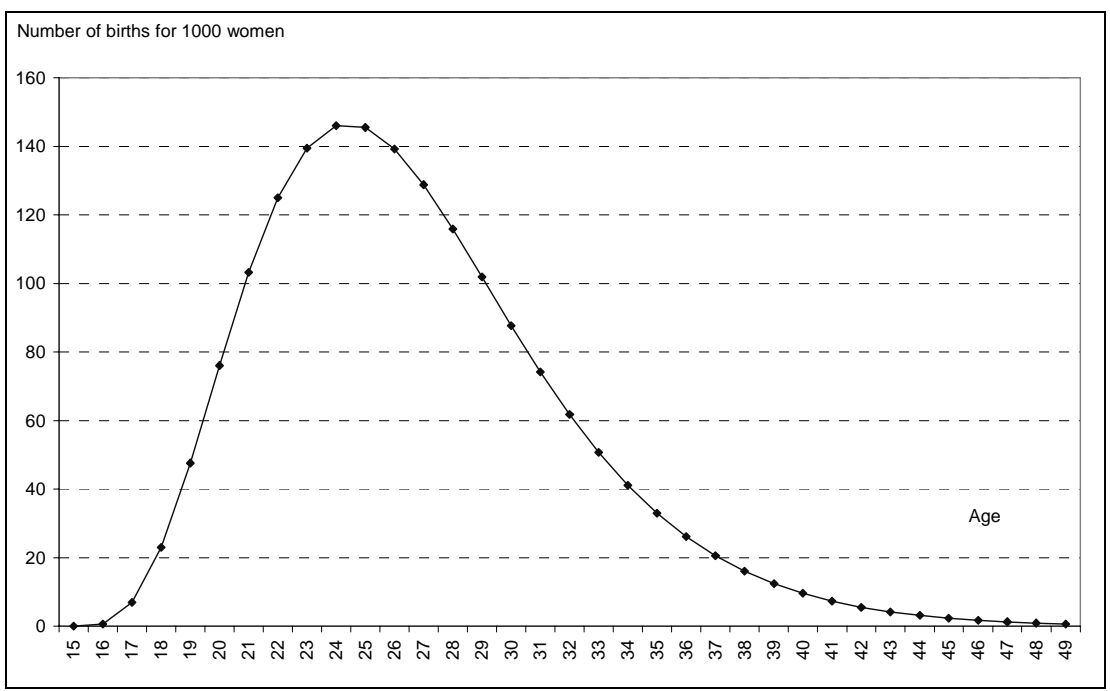

Comparison with the observed distribution

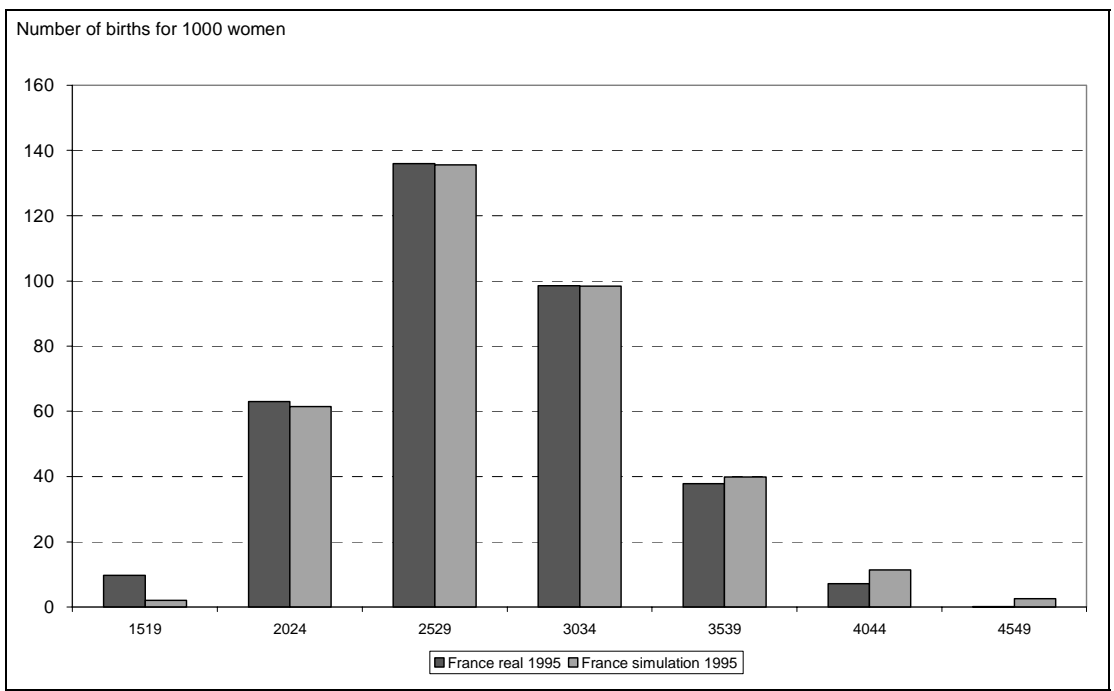


Figure 6 : Dependency ratio in the simulation model vs national projections
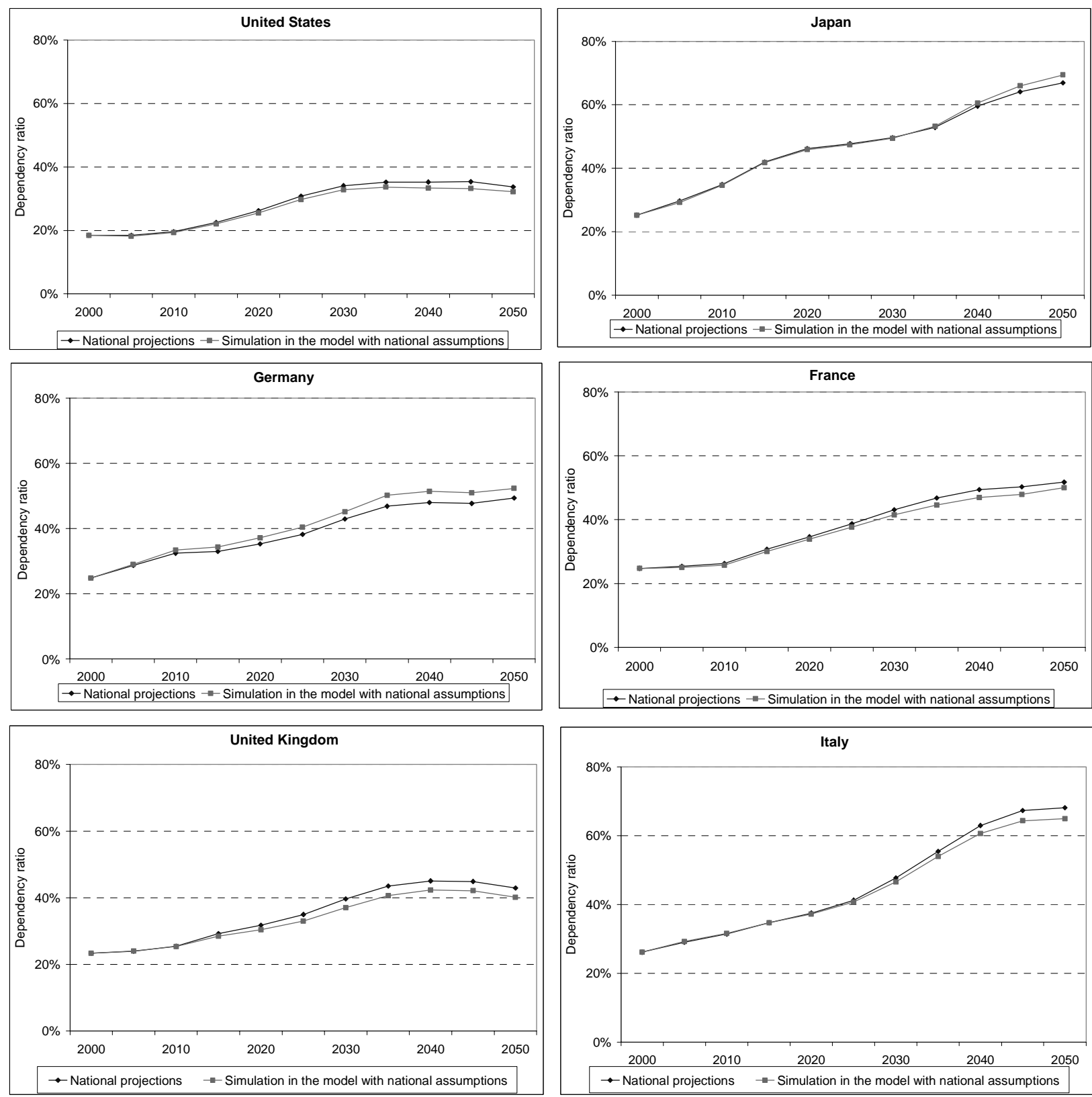
Figure 6 (cont'd): Dependency ratio in the simulation model vs national projections
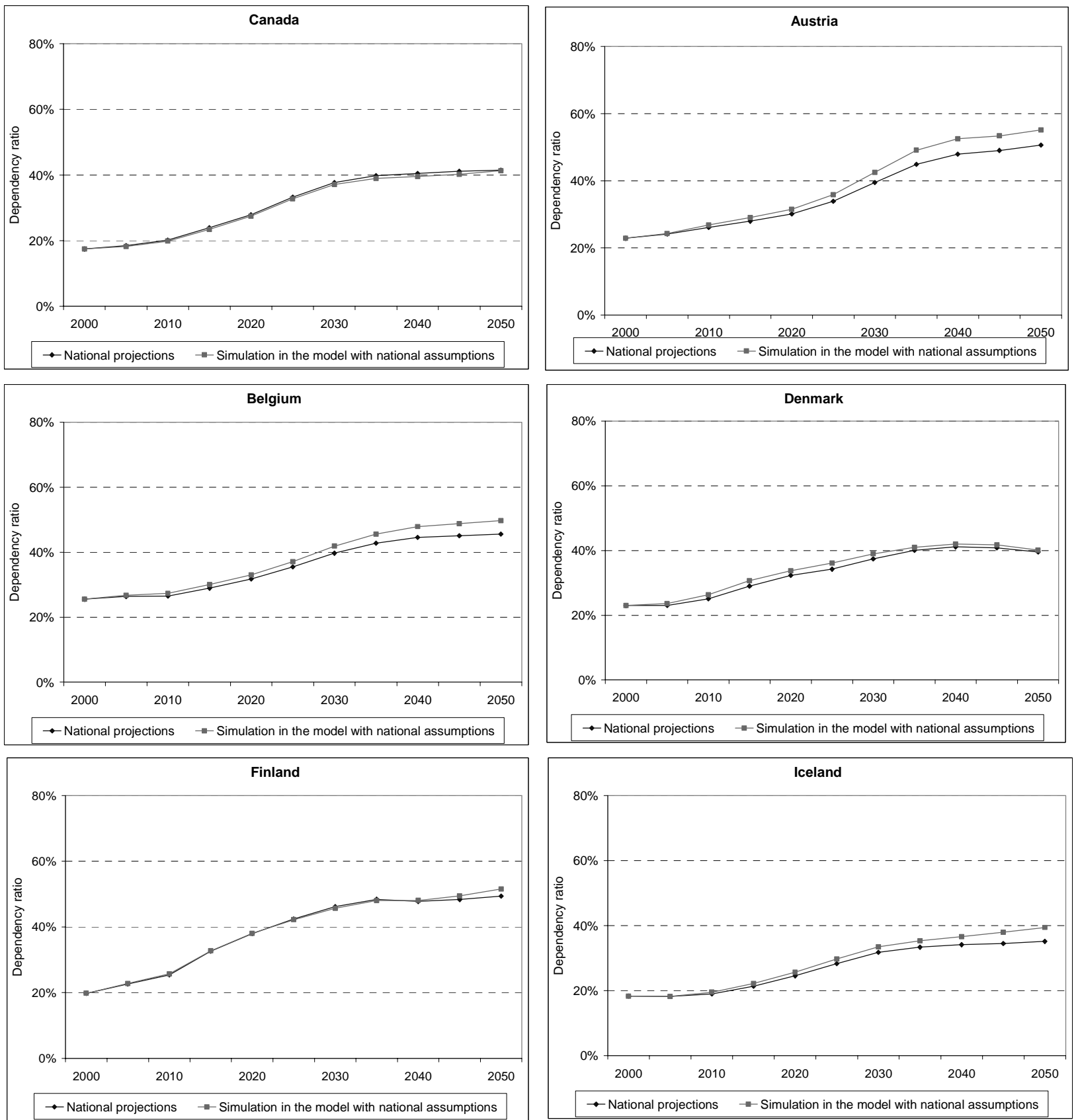
Figure 6 (cont'd): Dependency ratio in the simulation model vs national projections
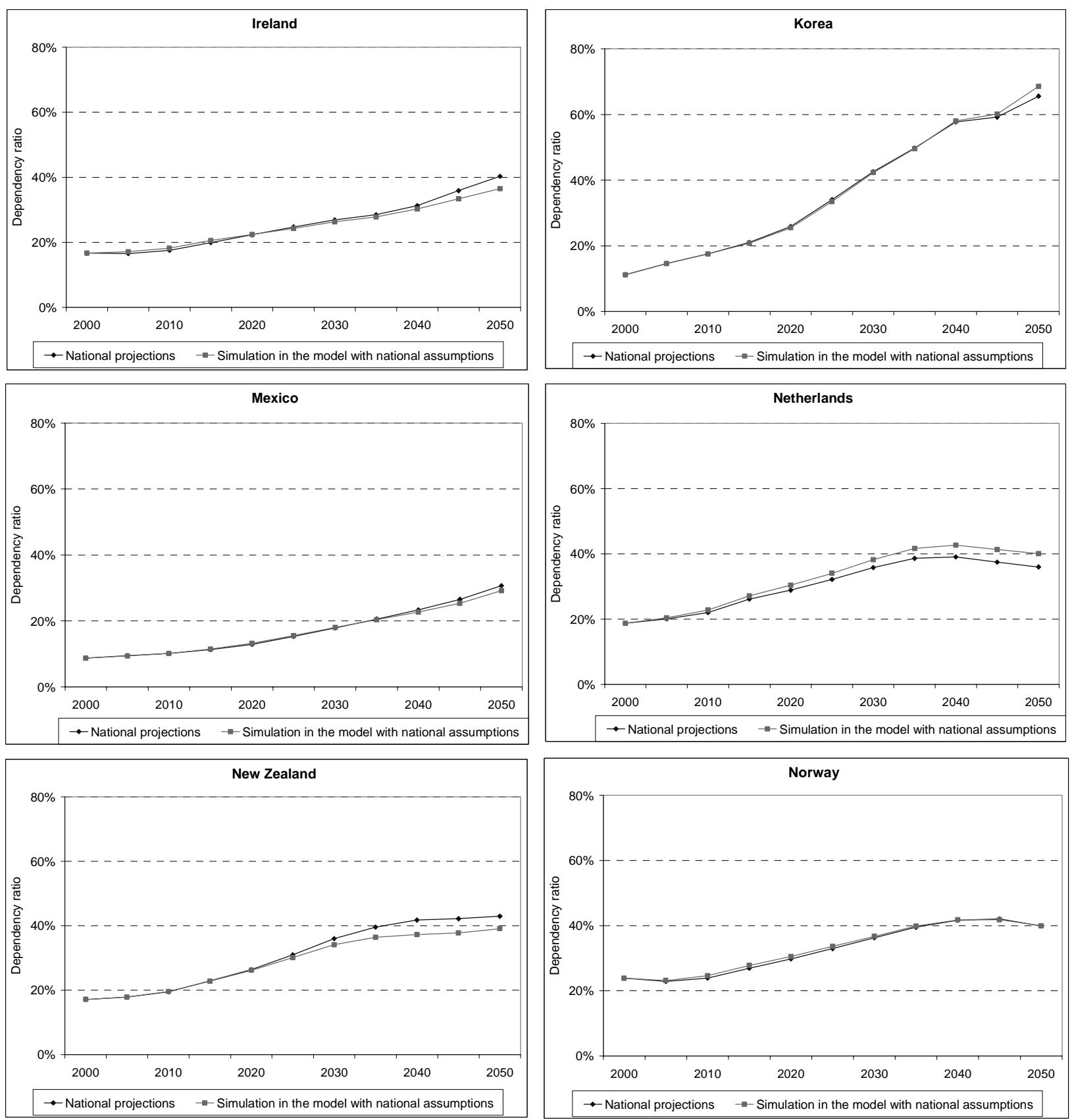
Figure 6 (cont'd): Dependency ratio in the simulation model vs national projections
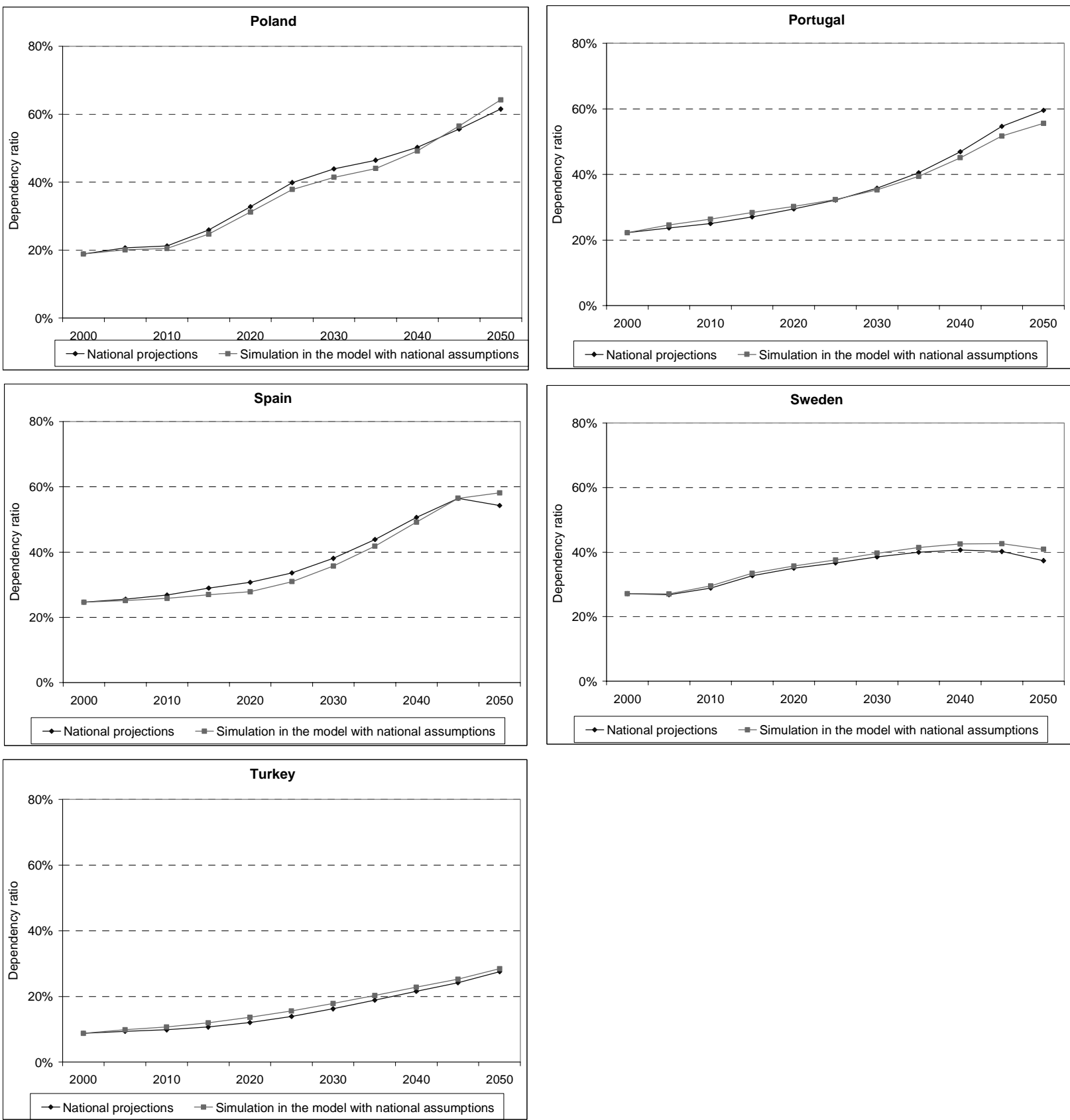
ECO/WKP(2005)51

Figure 7 : Differences between the structure of the population by age in the simulation model and in national projections
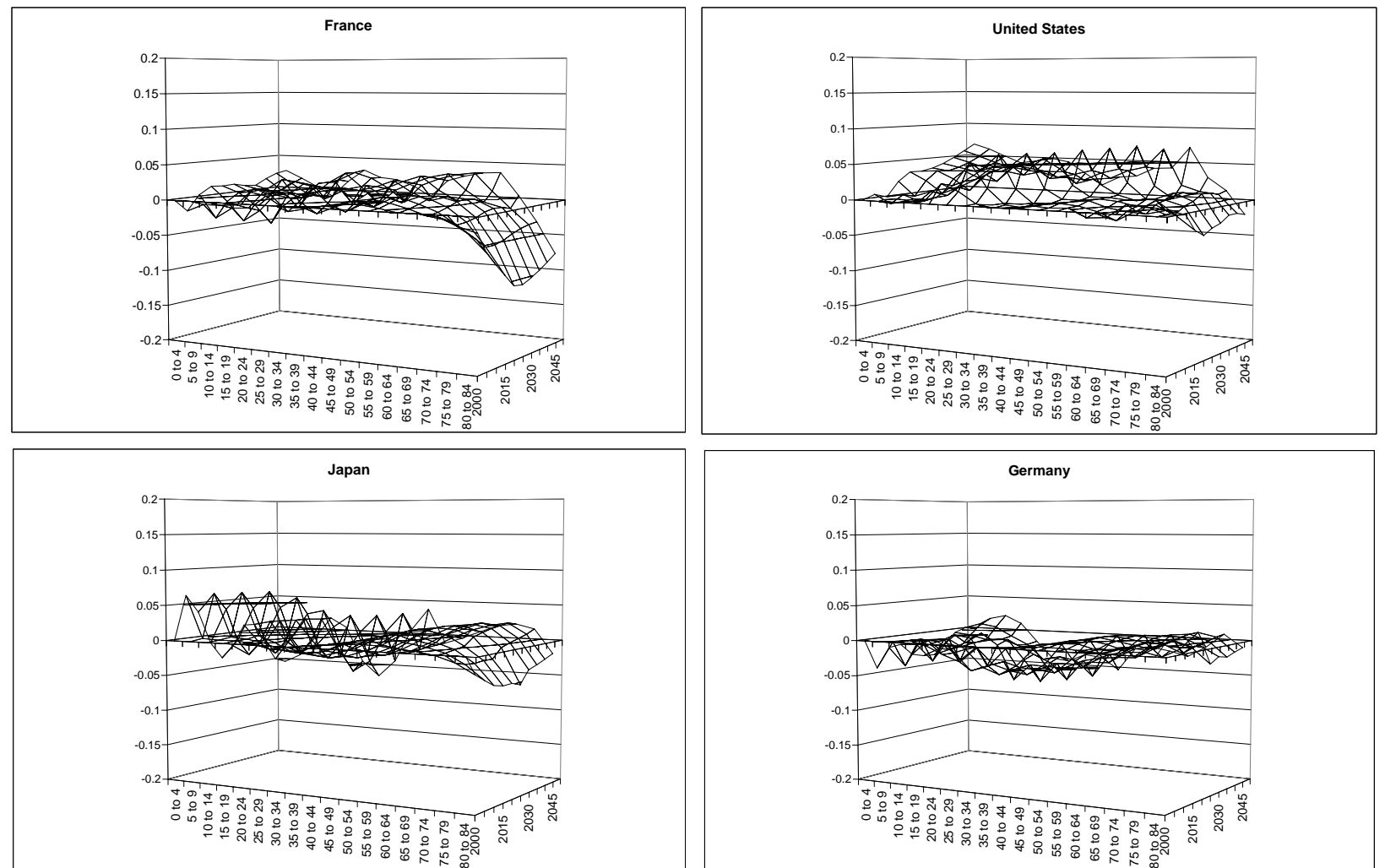
Figure 8 : Dependency ratio and future longevity gains
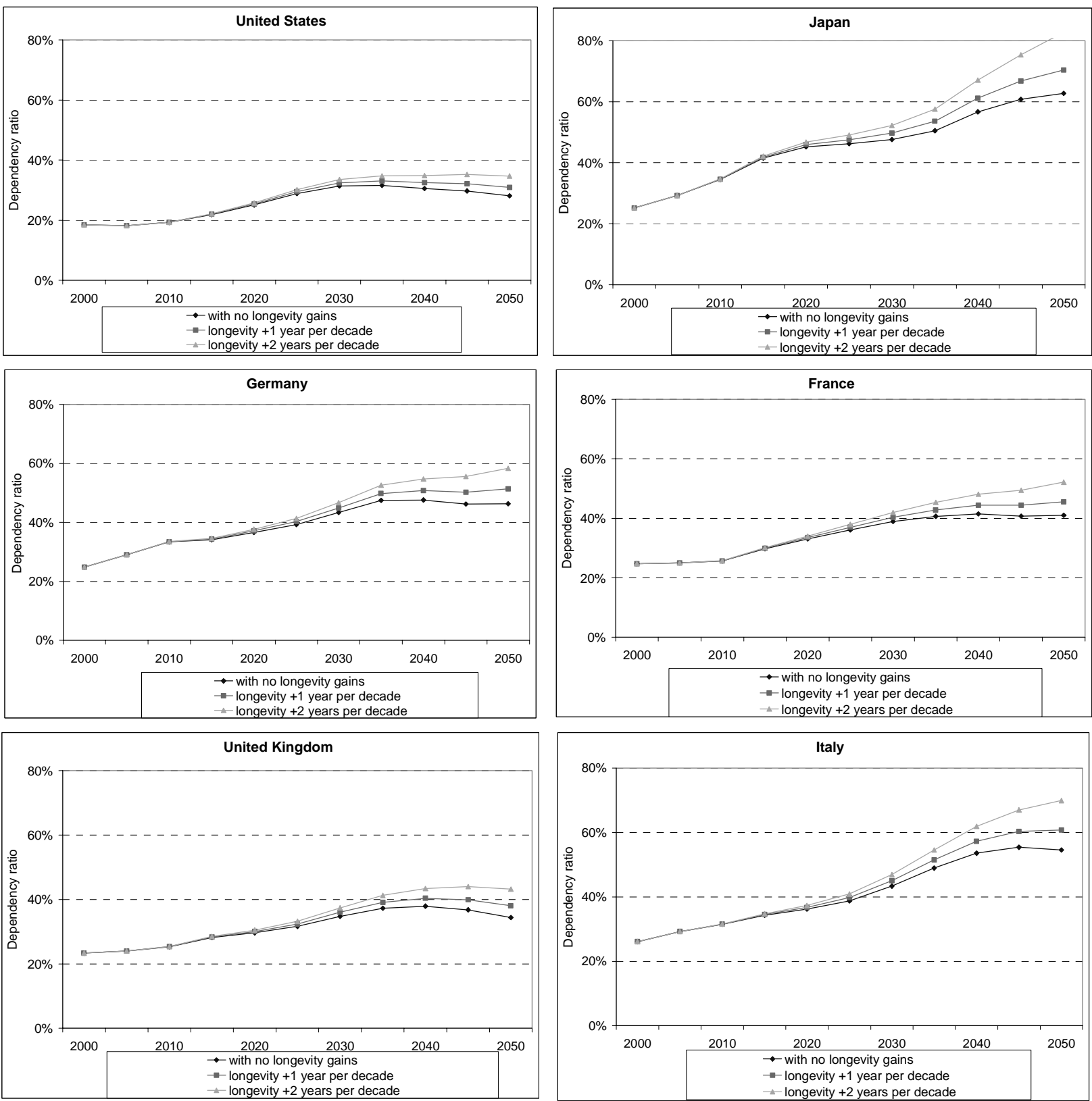
Figure 8 (cont'd): Dependency ratio and future longevity gains
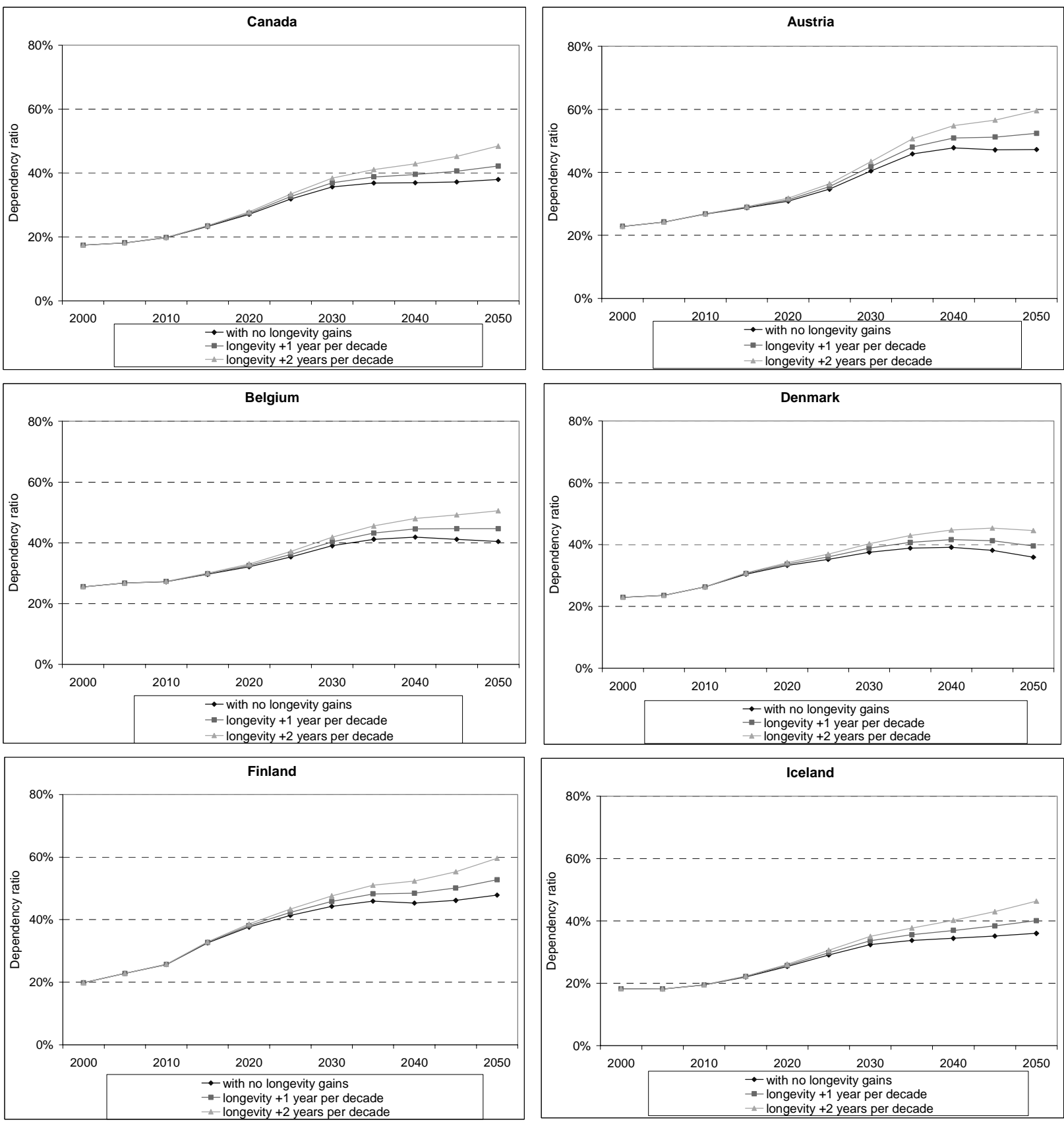
Figure 8 (cont'd): Dependency ratio and future longevity gains
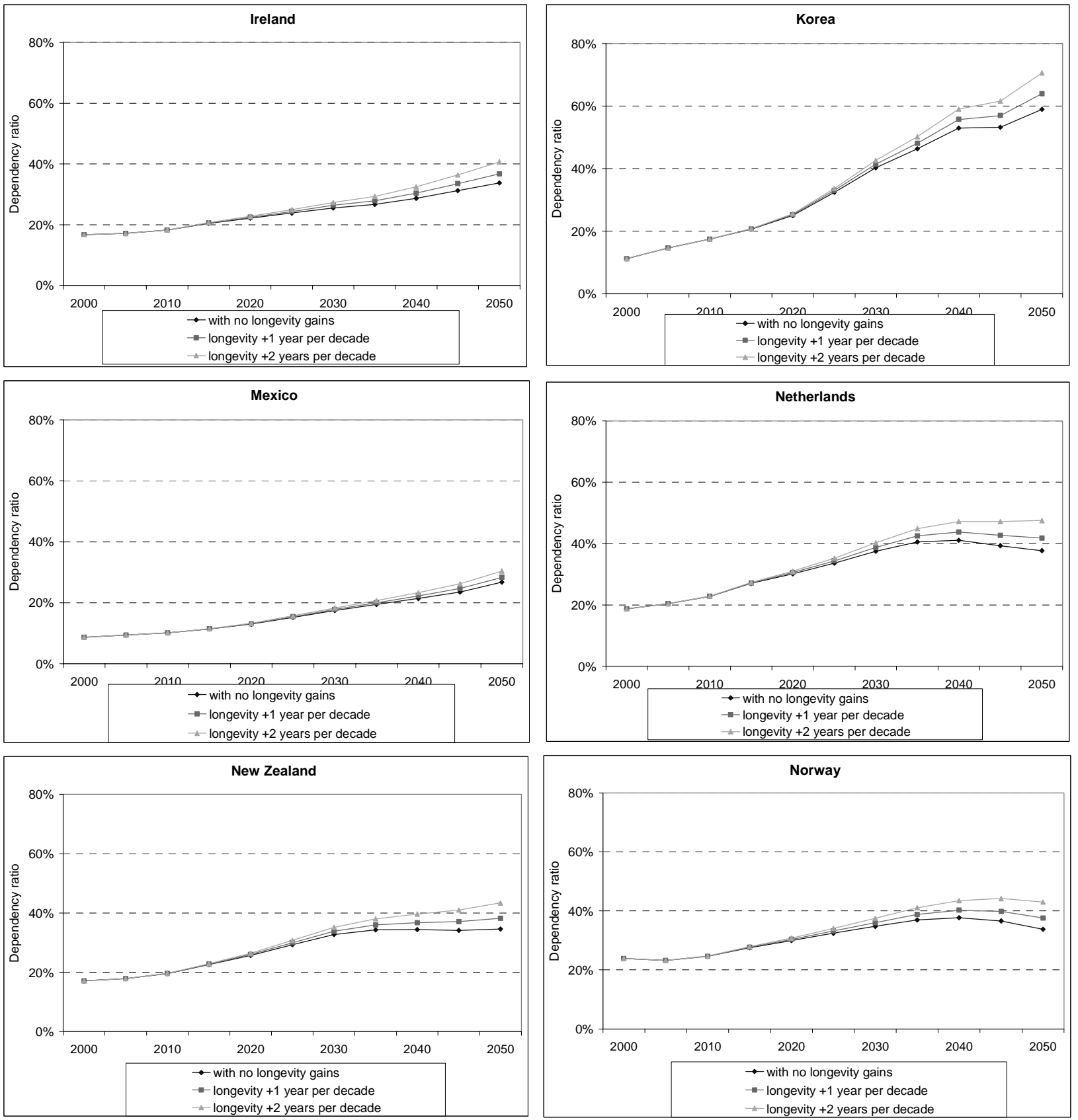
Figure 8 (cont'd): Dependency ratio and future longevity gains
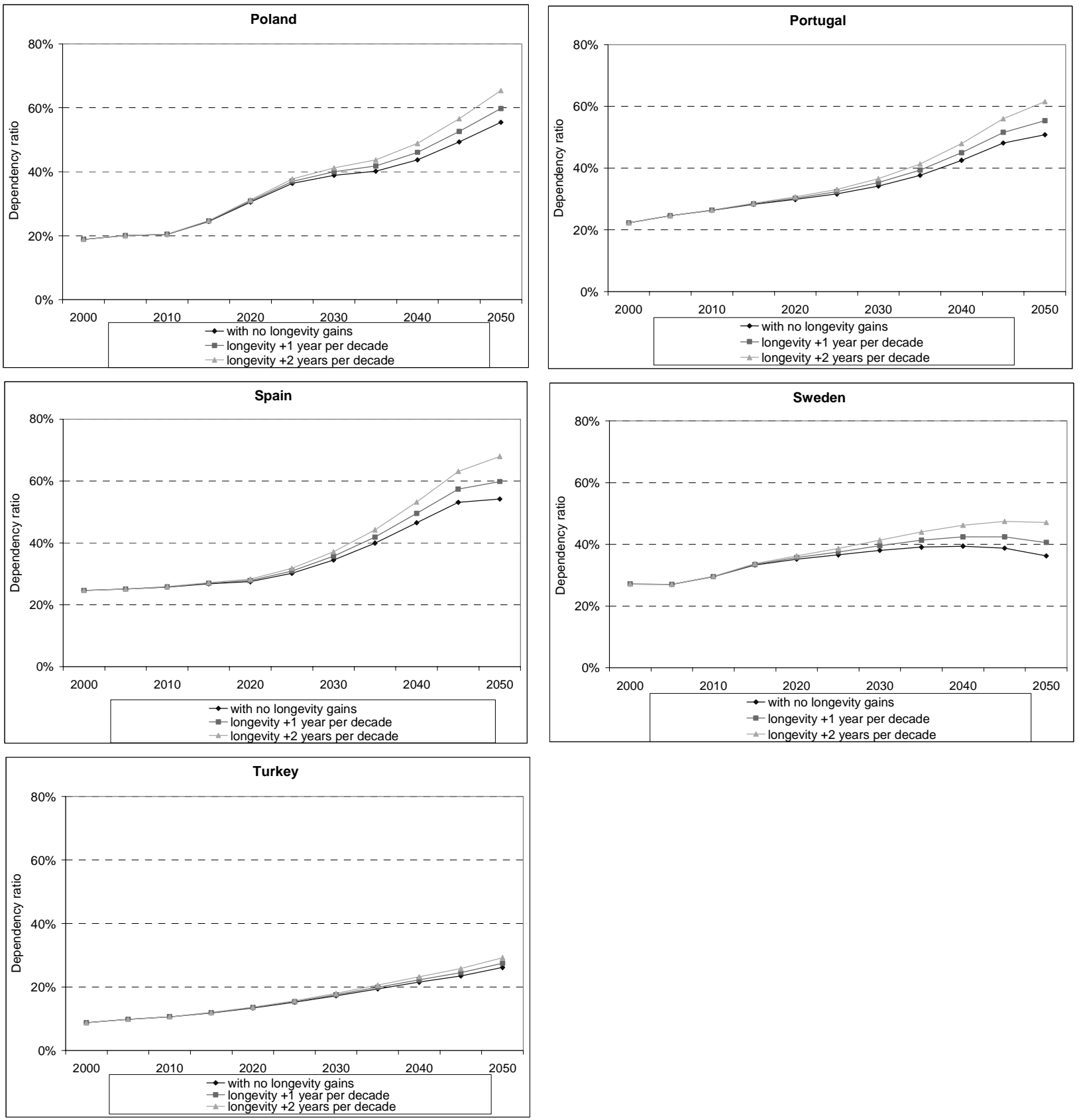
Figure 9 : Dependency ratio and future mortality at old age
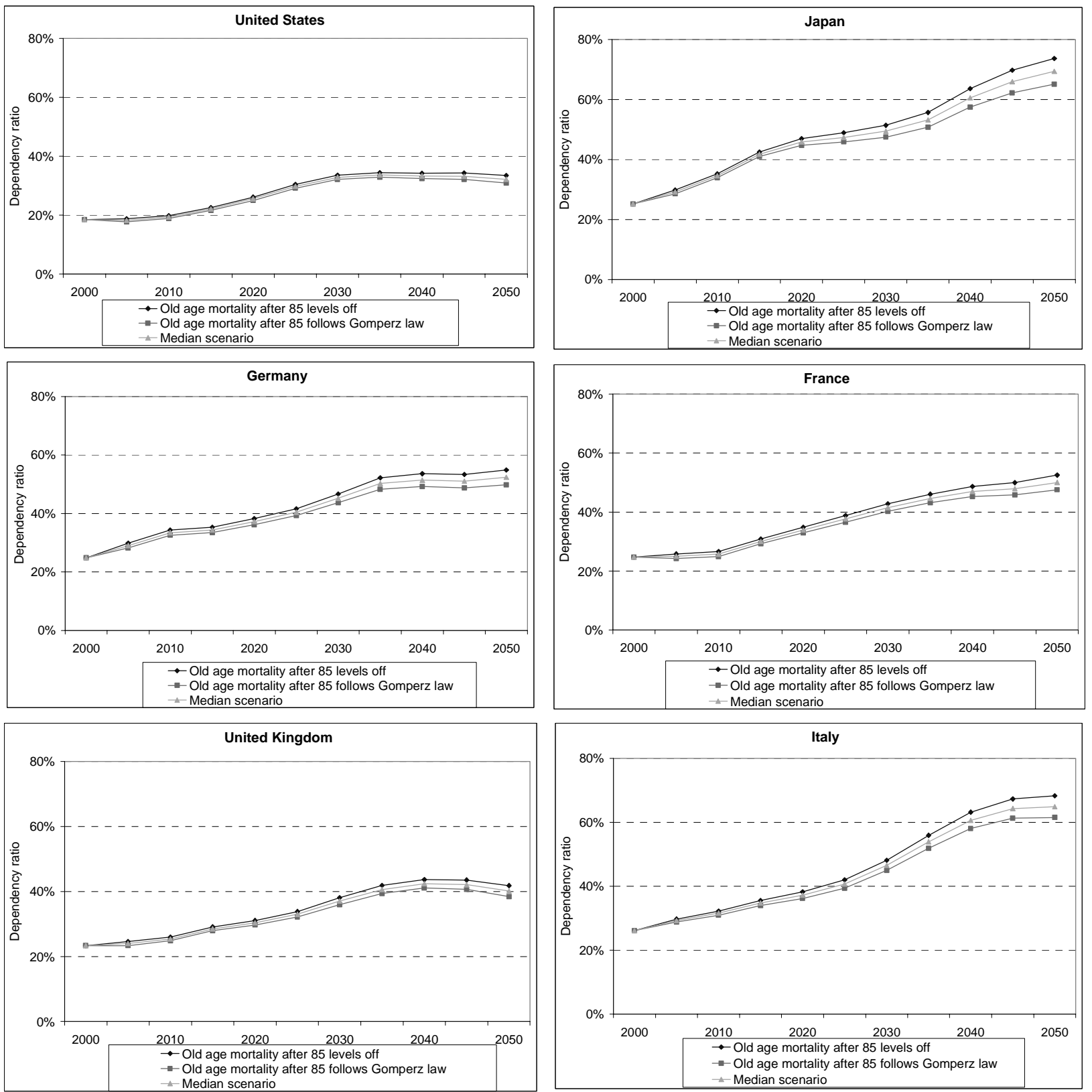
Figure 9 (cont'd) : Dependency ratio and future mortality at old age
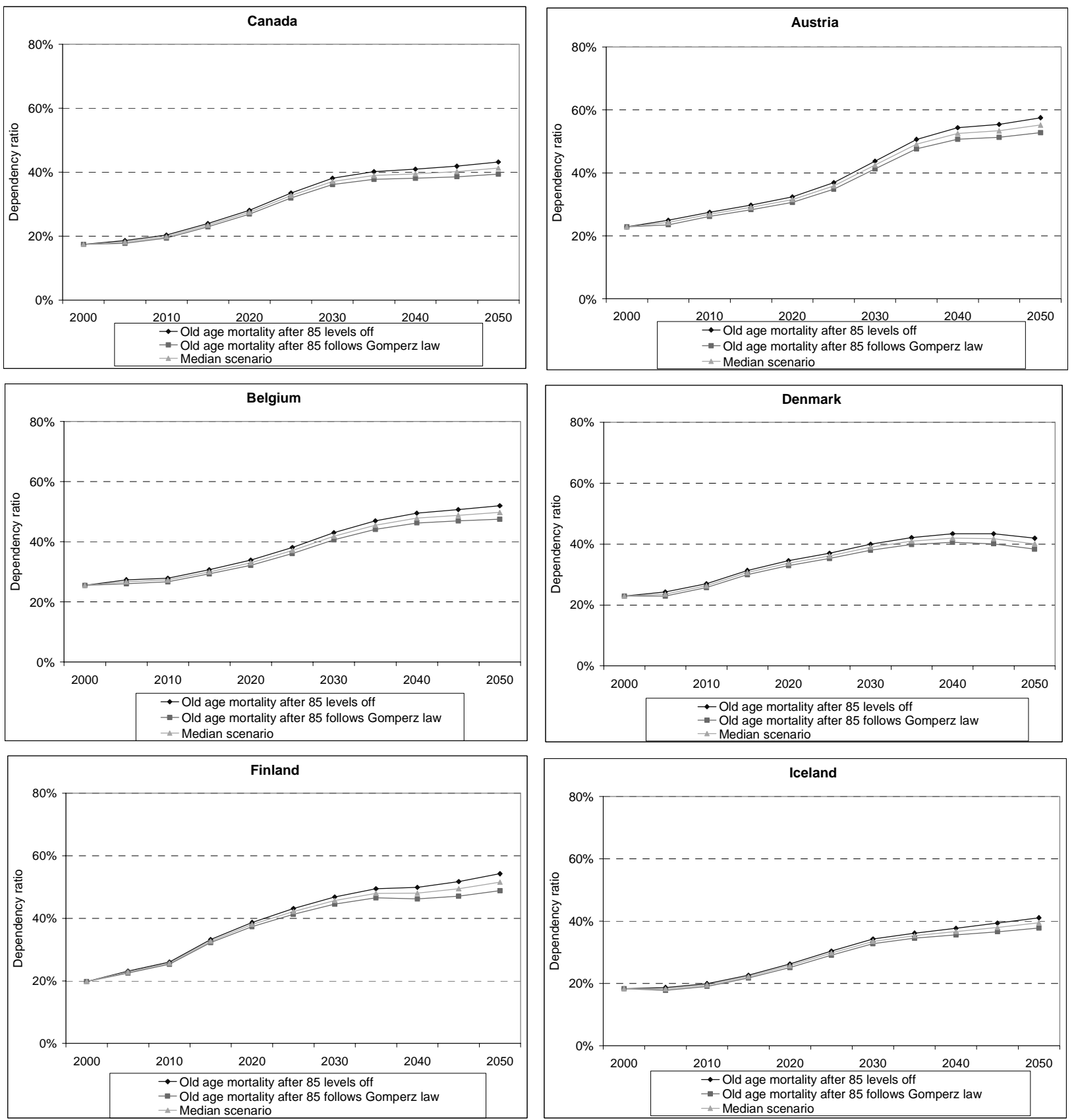
Figure 9 (cont'd) : Dependency ratio and future mortality at old age
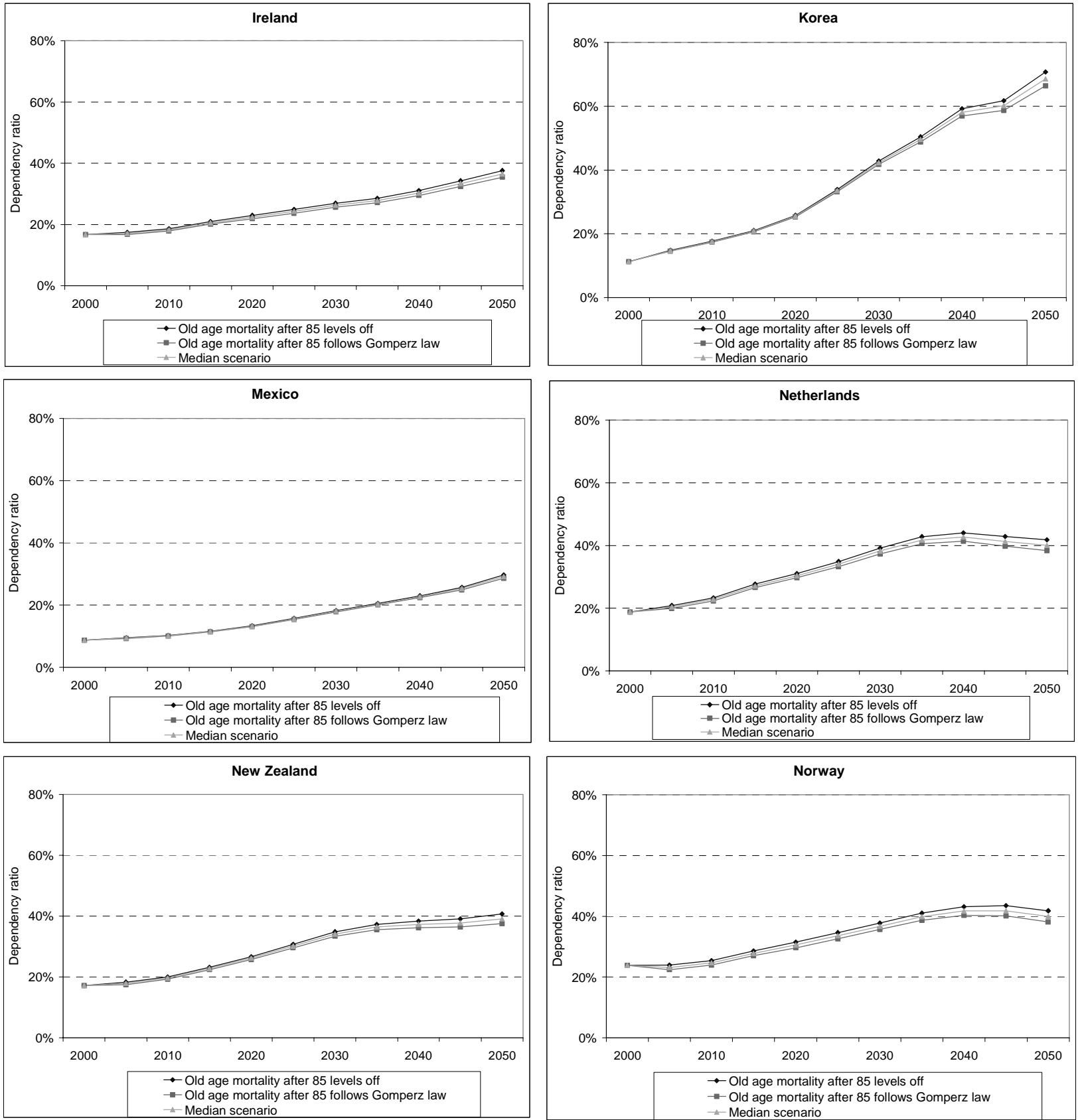
Figure 9 (cont'd) : Dependency ratio and future mortality at old age
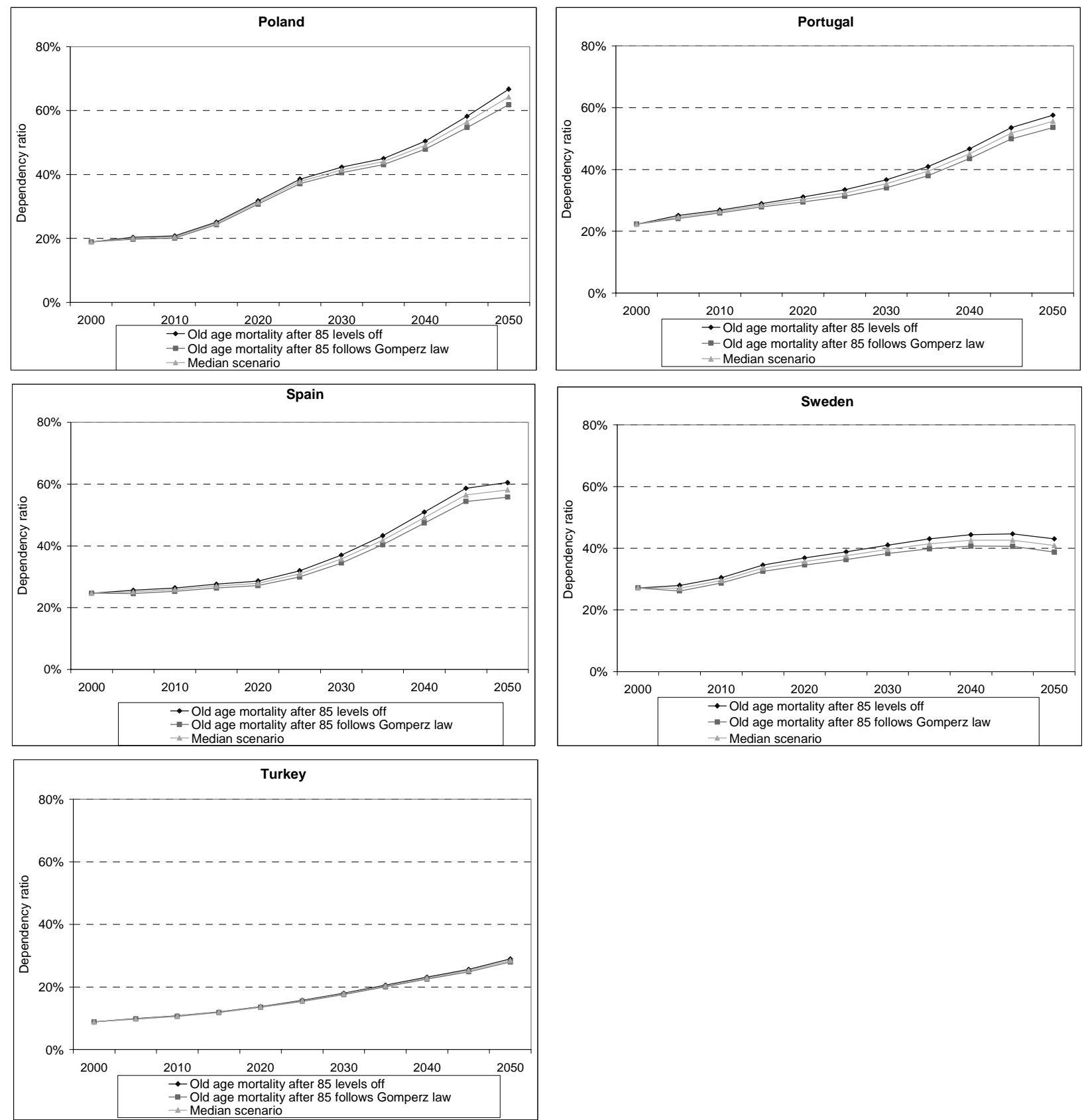
Figure 10 : Dependency ratio and fertility rate
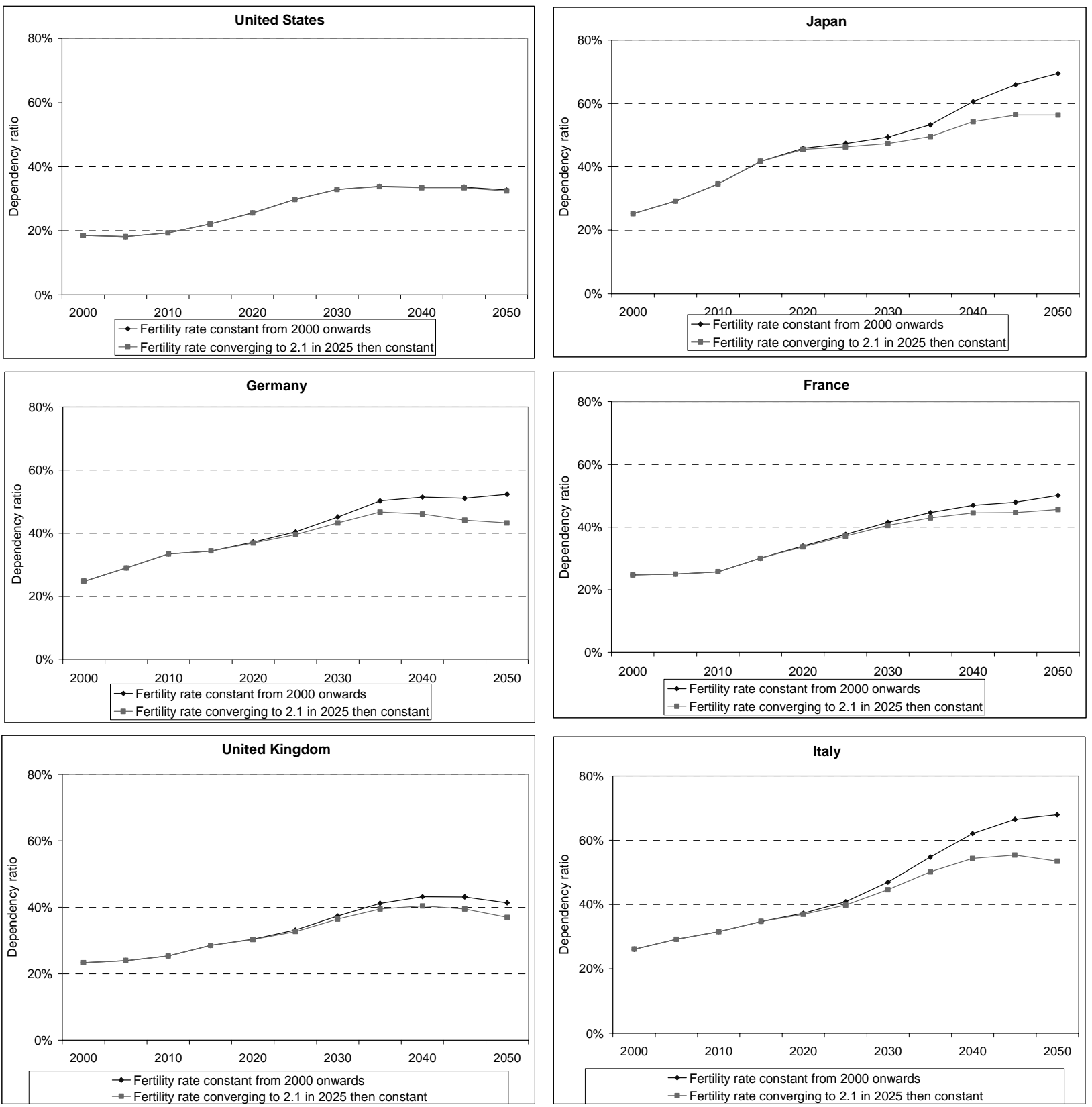
Figure 10 (cont'd) : Dependency ratio and fertility rate
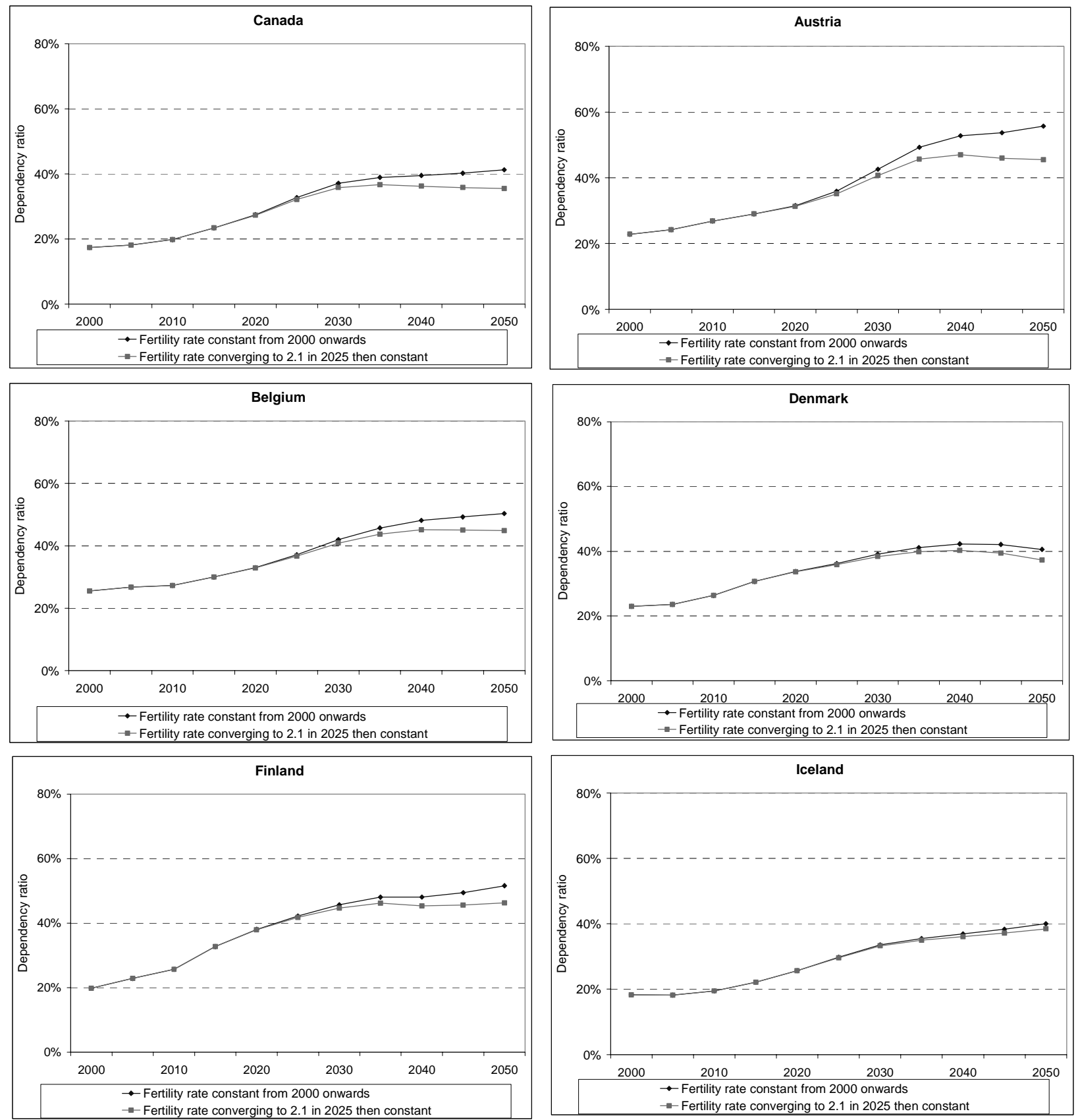
Figure 10 (cont'd) : Dependency ratio and fertility rate
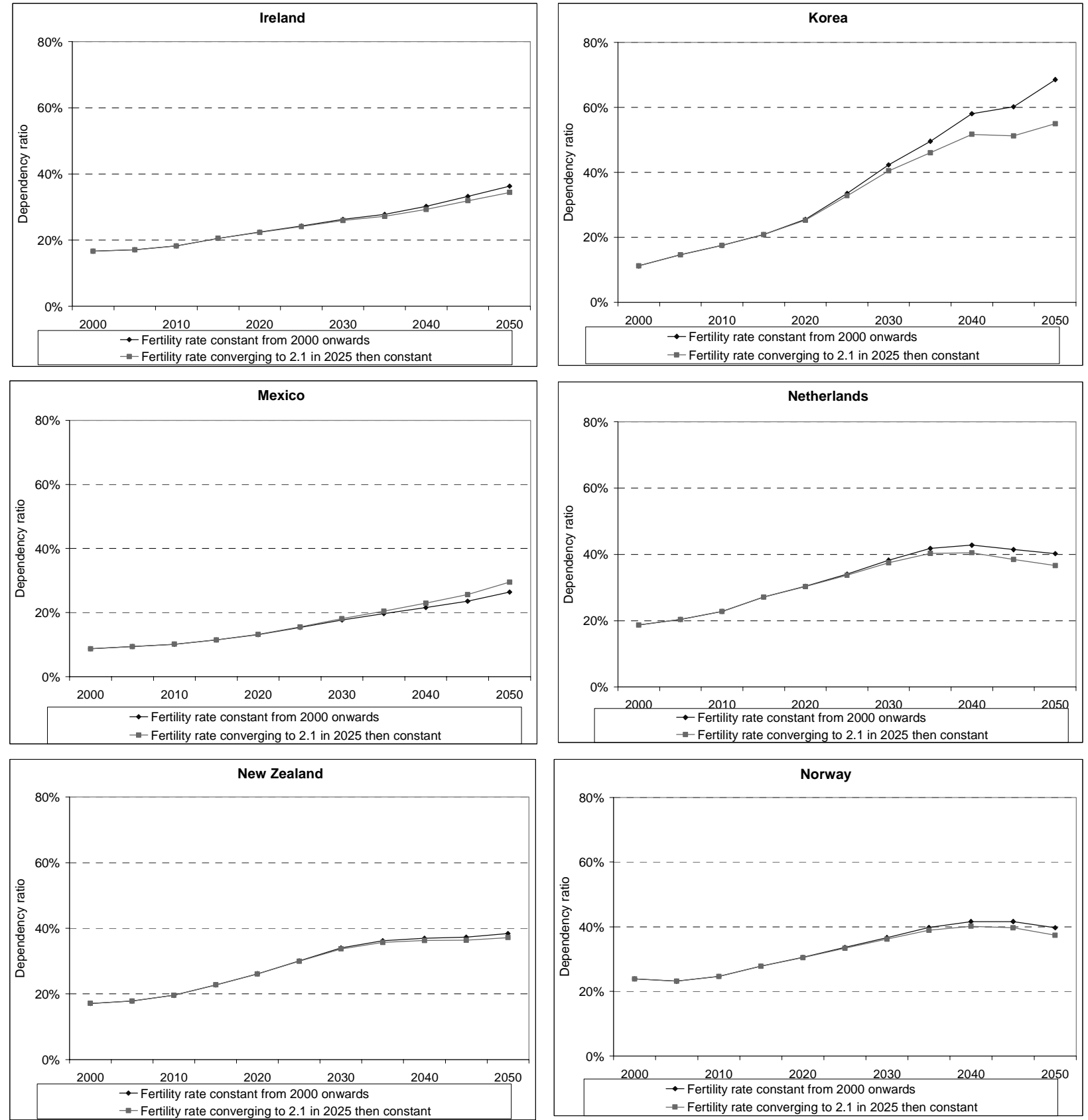
Figure 10 (cont'd) : Dependency ratio and fertility rate
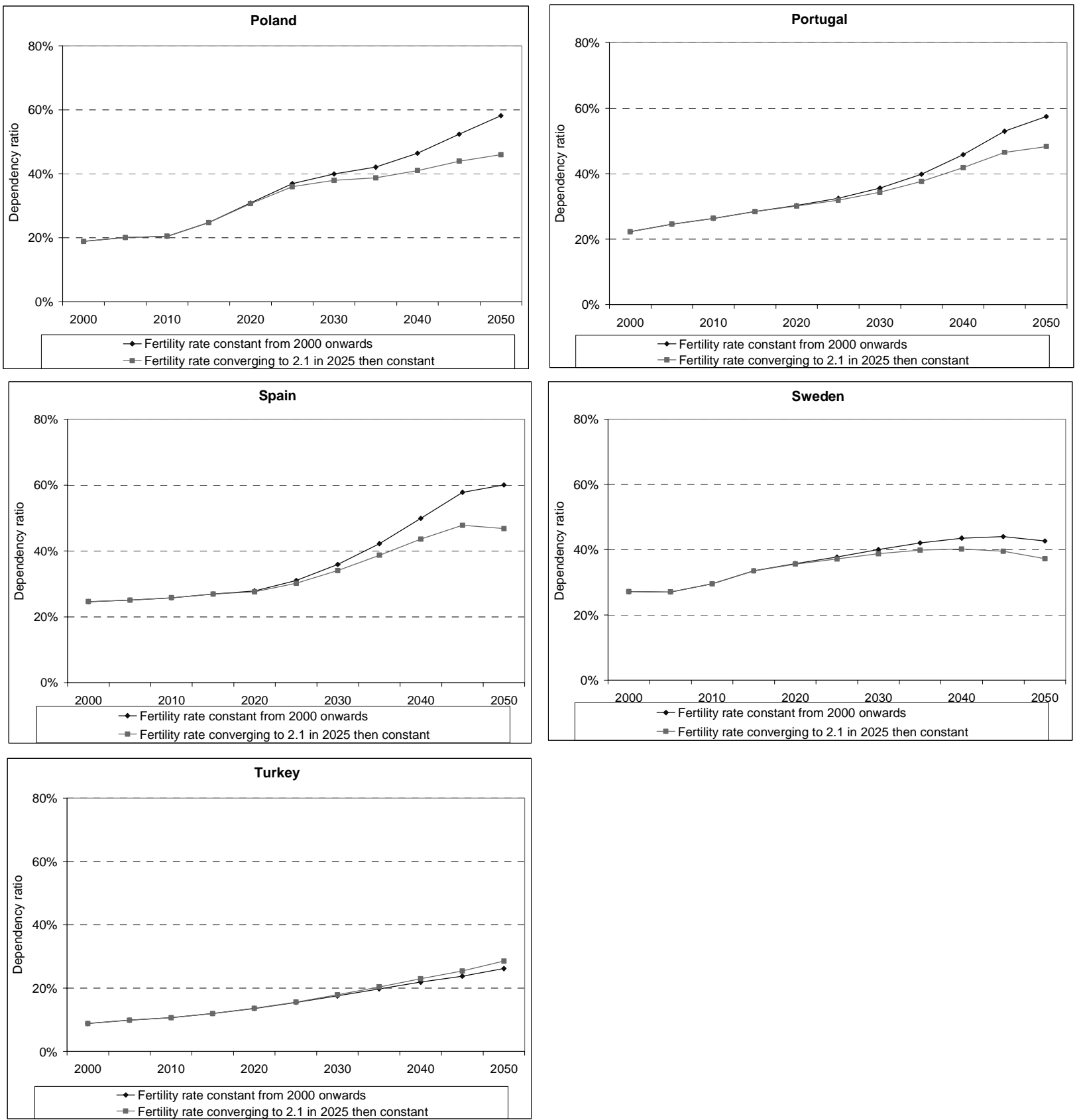
Figure 11 : Dependency ratio and net migration flows
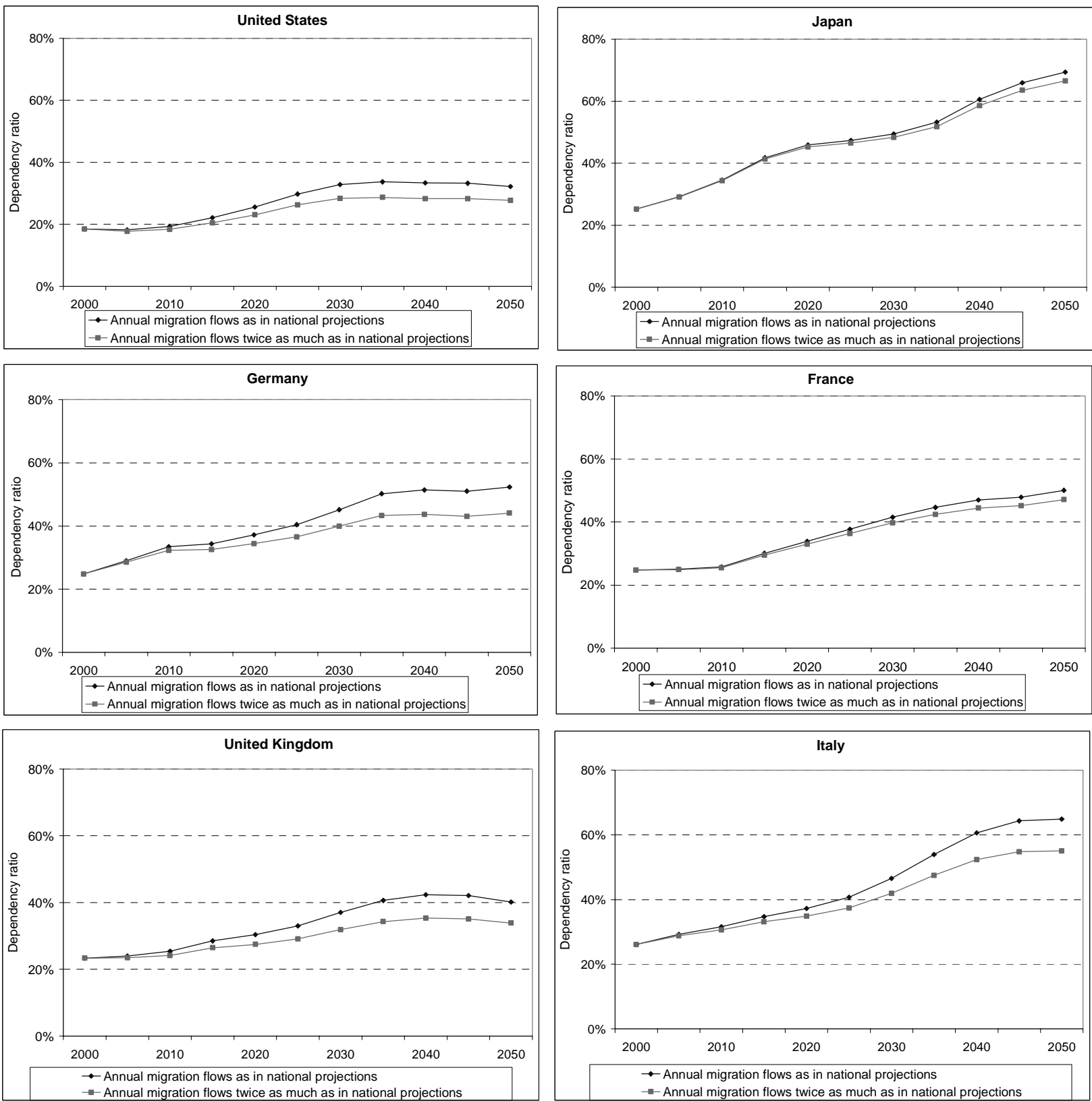
Figure 11 (cont'd) : Dependency ratio and net migration flows
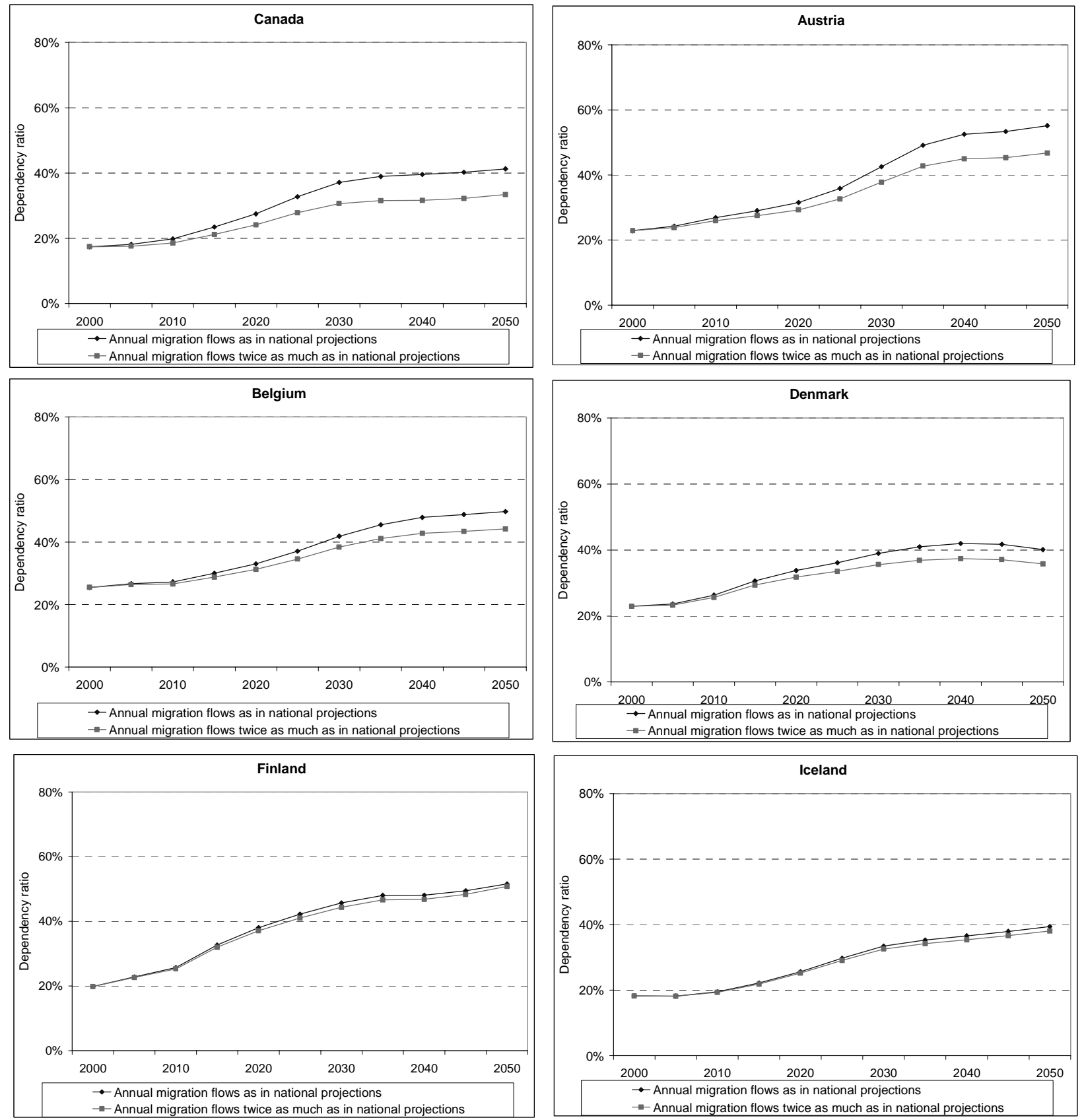
Figure 11 (cont'd) : Dependency ratio and net migration flows
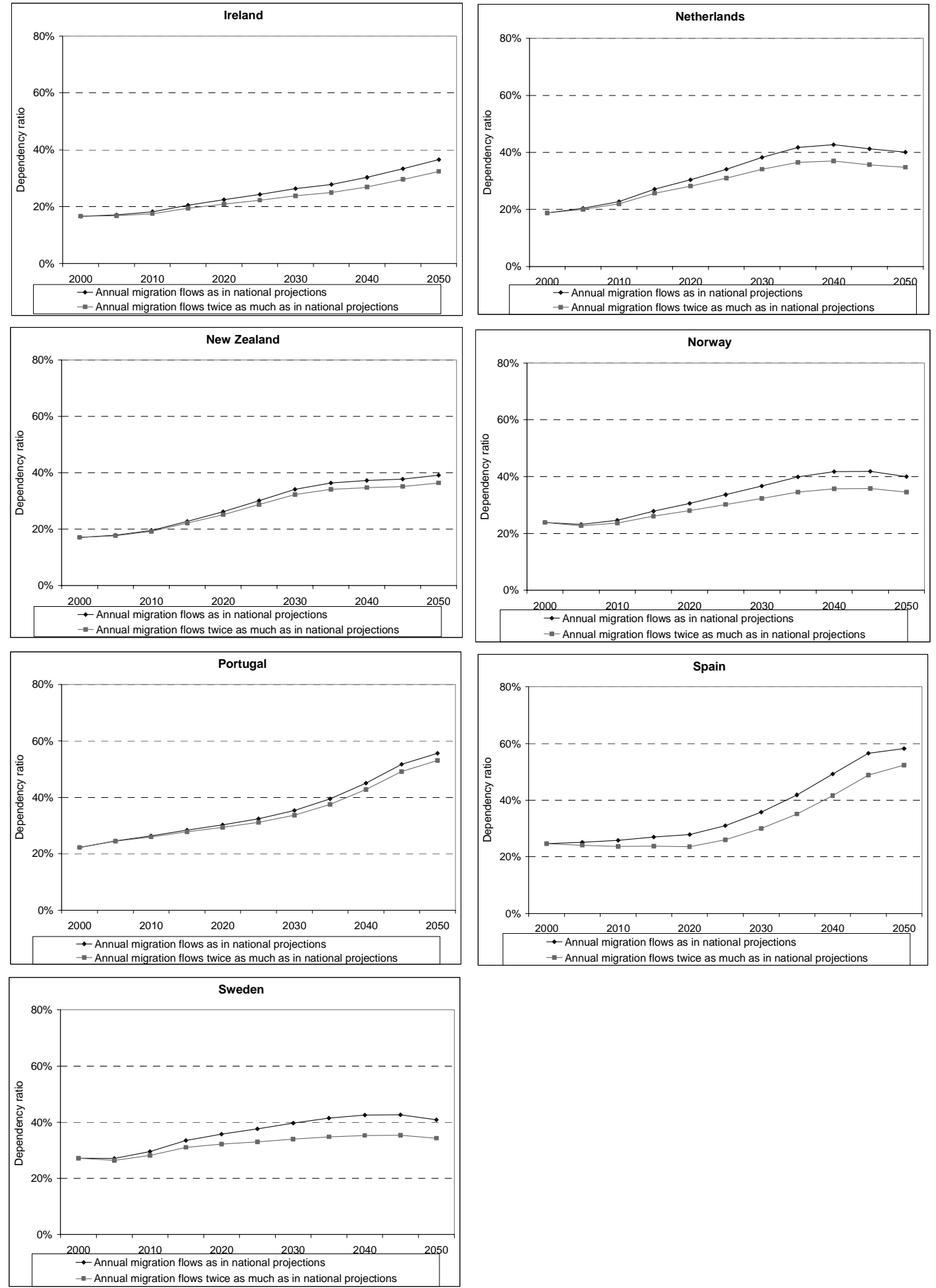
Figure 12 : Overall sensitivity range: upper- and lower-bound scenarios
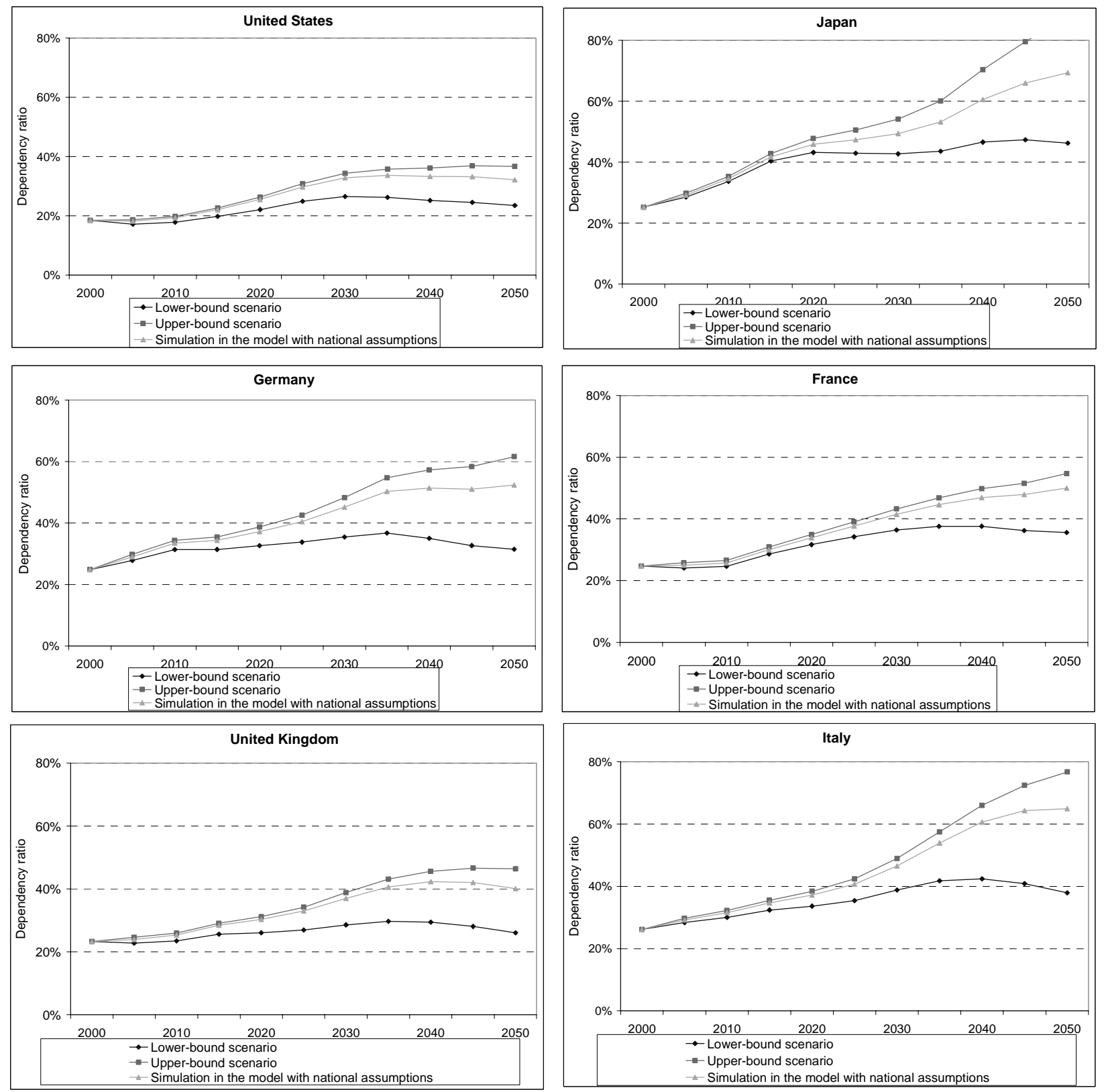
Figure 12 (cont'd) : Overall sensitivity range: upper- and lower-bound scenarios
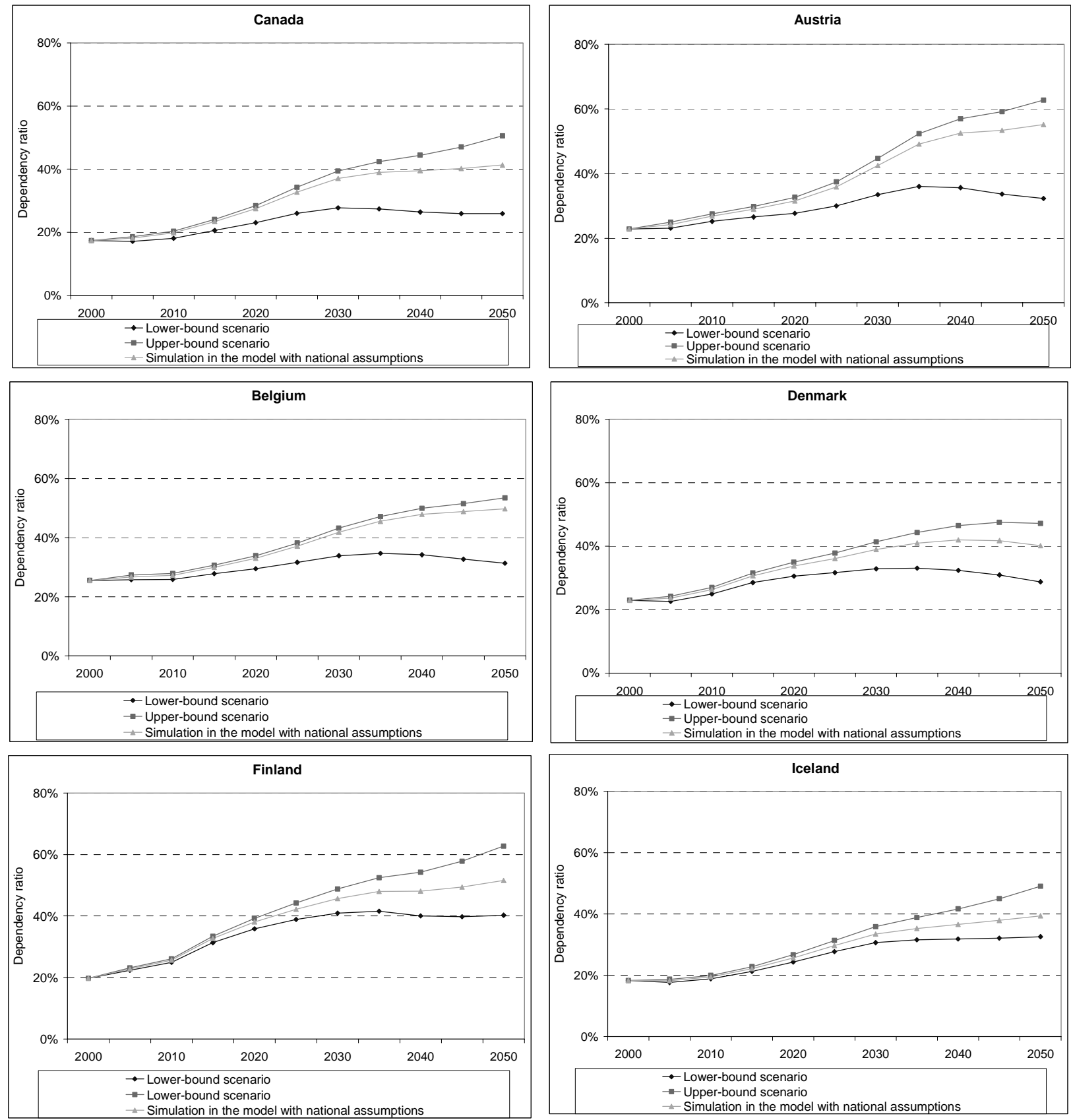
Figure 12 (cont'd) : Overall sensitivity range: upper- and lower-bound scenarios
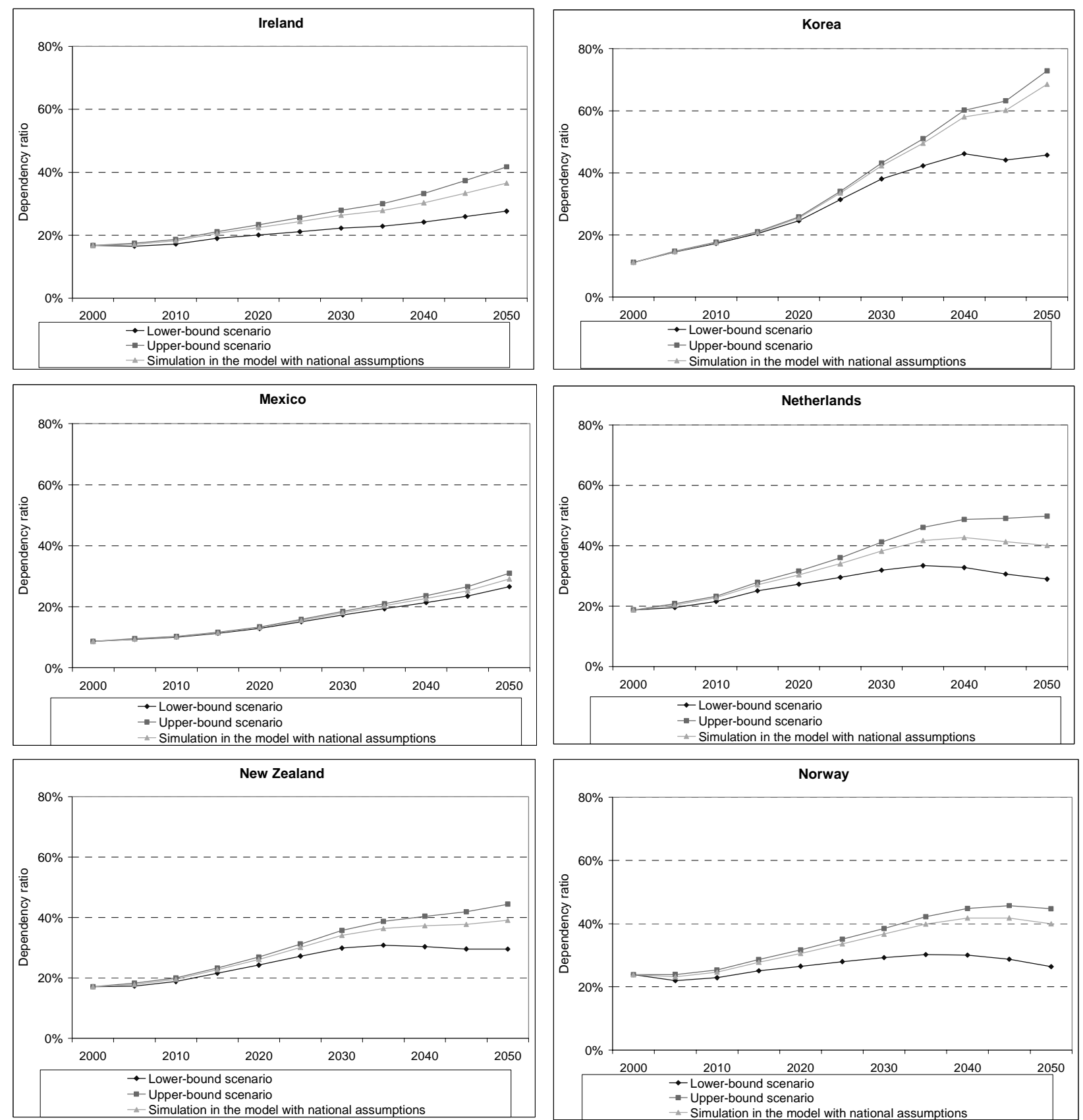
Figure 12 (cont'd) : Overall sensitivity range: upper- and lower-bound scenarios
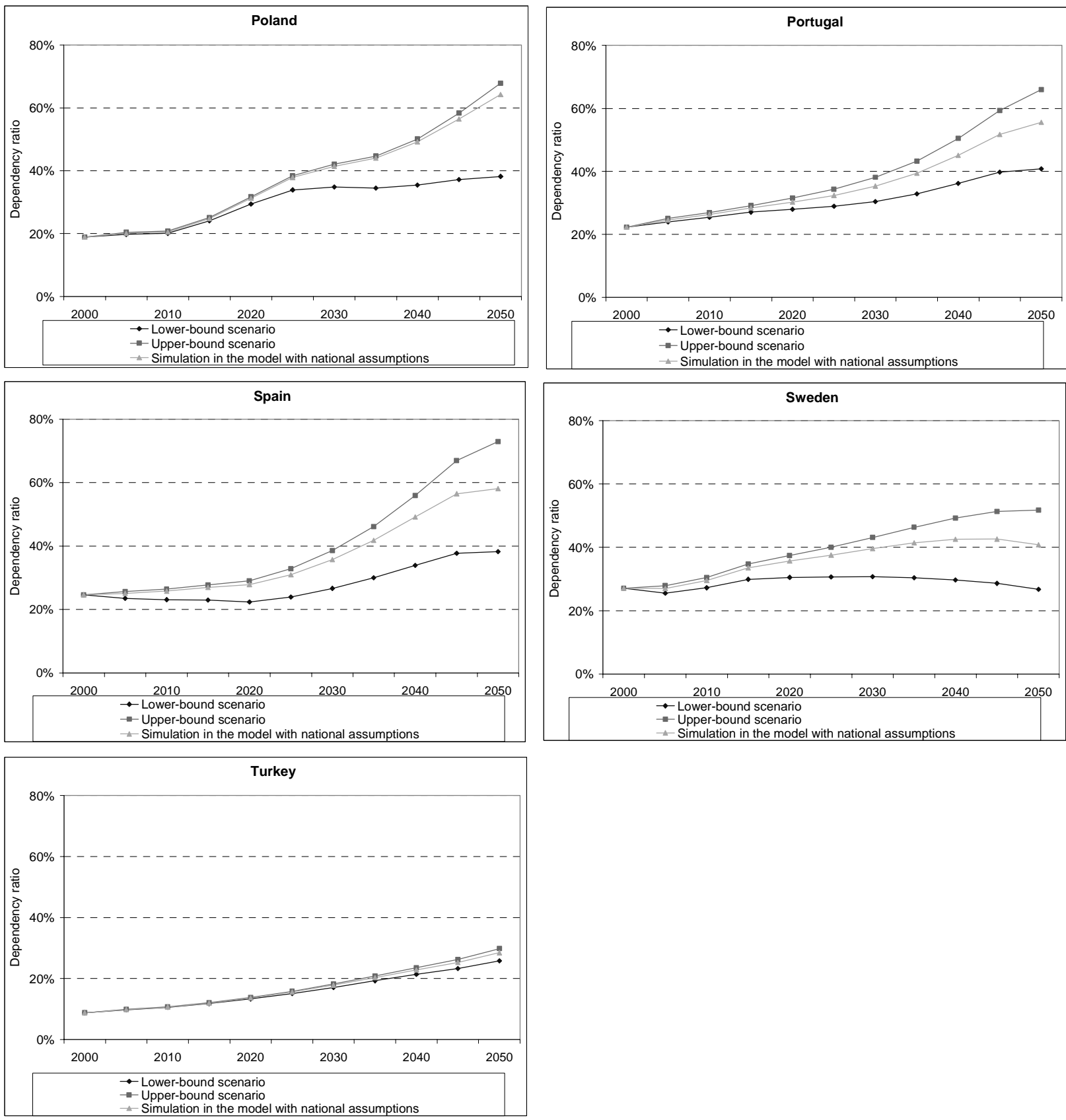
Figure 13 : High longevity and fertility vs low longevity and fertility scenarios
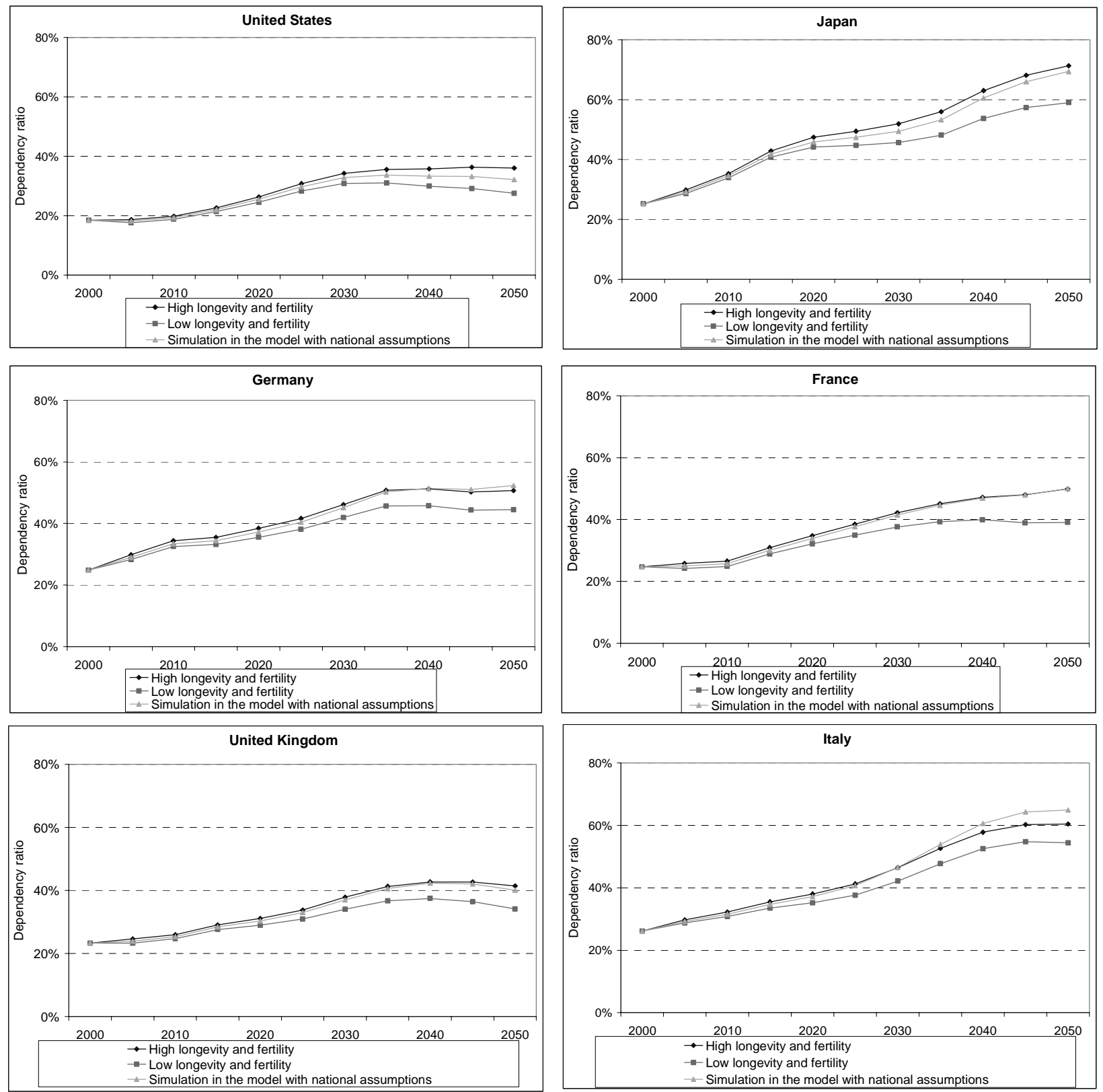
Figure 13 (cont'd) : High longevity and fertility vs low longevity and fertility scenarios
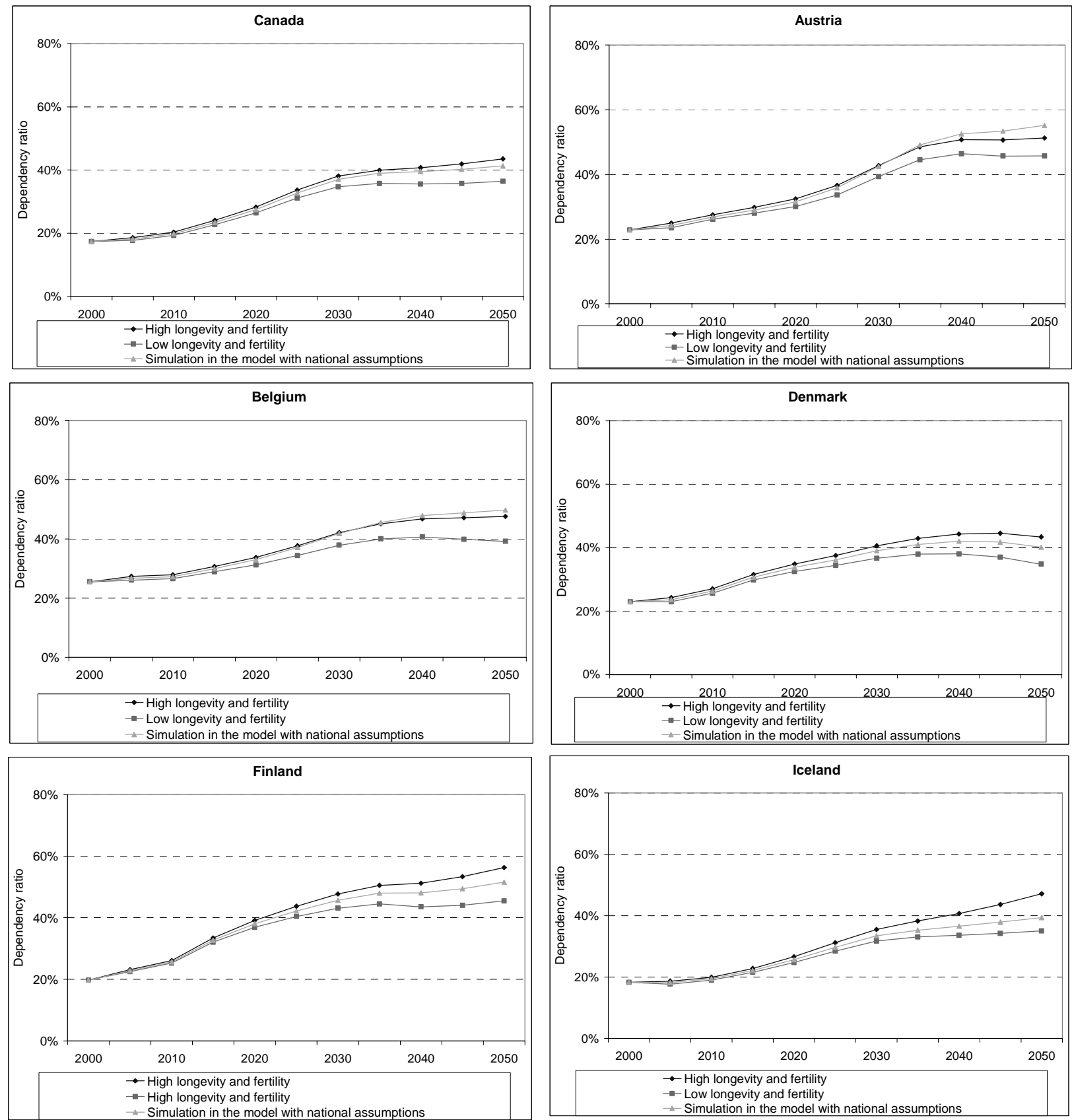
Figure 13 (cont'd) : High longevity and fertility vs low longevity and fertility scenarios
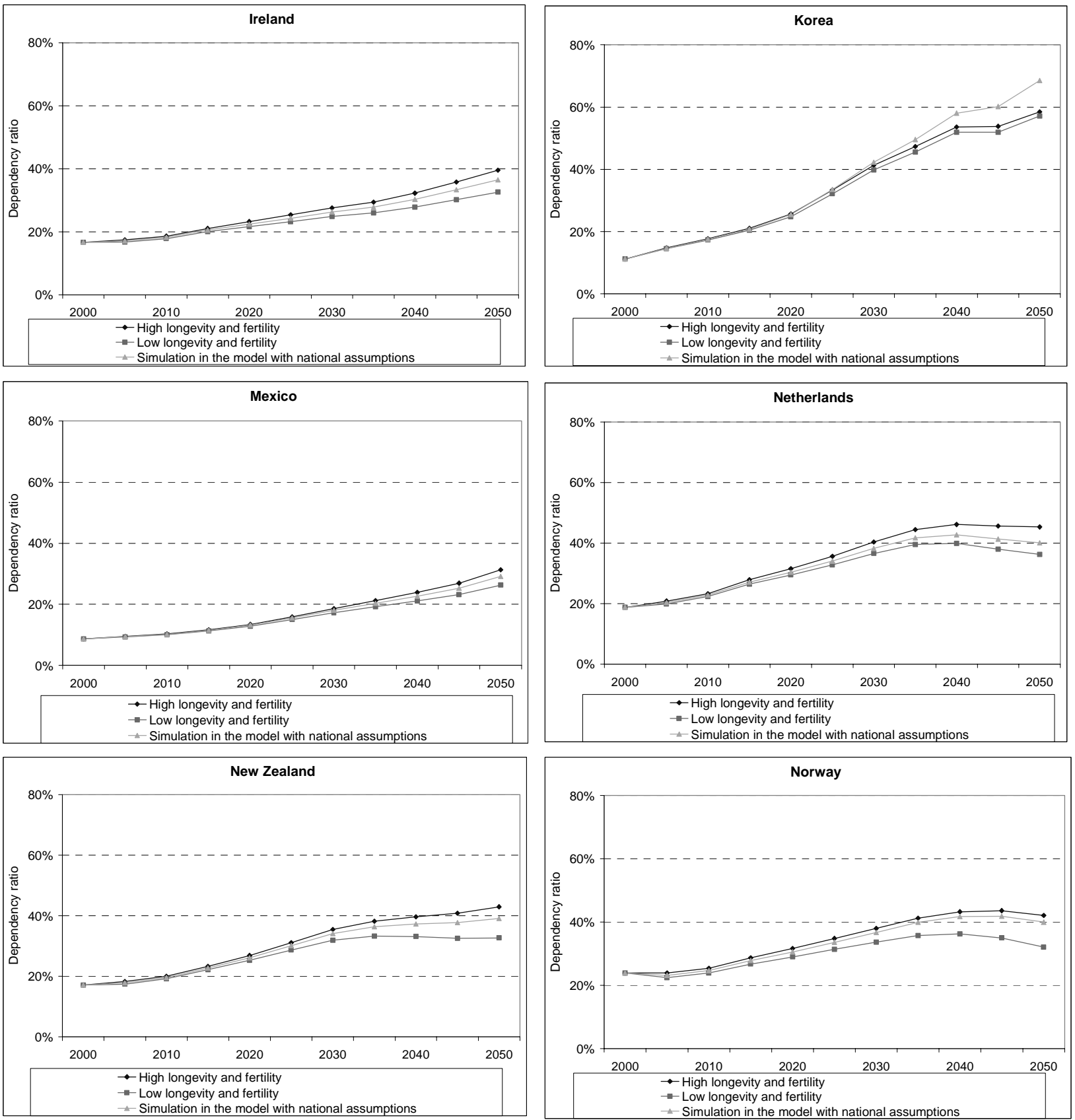
Figure 13 (cont'd) : High longevity and fertility vs low longevity and fertility scenarios
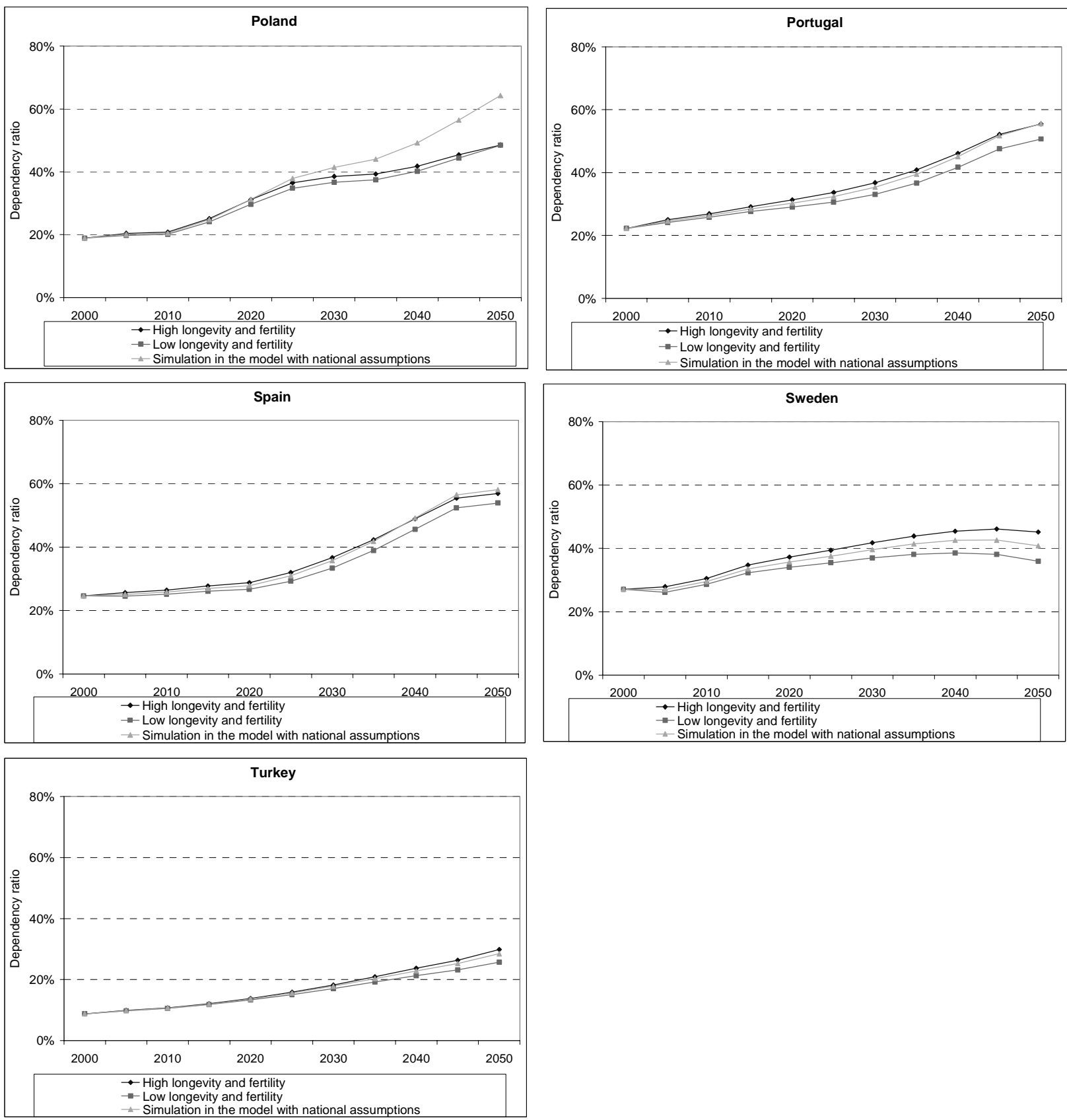
ECO/WKP(2005)51

\section{WORKING PAPERS}

The full series of Economics Department Working Papers can be consulted at www.oecd.org/eco/Working_Papers/

463. The Benefits of Liberalising Product Markets and Reducing Barriers to International Trade and Investment in the OECD

(December 2005)

462. Fiscal relations across levels of government in the United States

(November 2005) Thomas Laubach

461. Assessing the value of indicators of underlying inflation for monetary policy (November 2005) Pietro Catte and Torsten Sløk.

460. Regulation and economic performance: product market reforms and productivity in the OECD (November 2005) Giuseppe Nicoletti and Stefano Scarpetta.

459. Innovation in the Business Sector

(November 2005) Florence Jaumotte and Nigel Pain

458. From Innovation Development to Implementation: Evidence from the Community Innovation Survey (November 2005) Florence Jaumotte and Nigel Pain

457. From Ideas to Development: the Determination of $R \& D$ and Patenting (November 2005) Florence Jaumotte and Nigel Pain

456. An Overview of Public Policies to Support Innovation (November 2005) Florence Jaumotte and Nigel Pain

455. Strengthening Regulation in Chile: The Case of Network Industries (November 2005) Alexander Galetovic and Luiz de Mello

454. Fostering Innovation in Chile

(November 2005) José-Miguel Benavente, Luiz de Mello and Nanno Mulder

453. Getting the most out of public sector decentralisation in Mexico (October 2005) Isabelle Joumard

452. Raising Greece's Potential Output Growth (October 2005) Vassiliki Koutsogeorgopoulou and Helmut Ziegelschmidt

451. Product Market Competition and Economic Performance in Australia (October 2005) Helmut Ziegelschmidt, Vassiliki Koutsogeorgopoulou, Simen Bjornerud and Michael Wise

450. House Prices and Inflation in the Euro Area (October 2005) Boris Cournède

449. The EU's Single Market: At Your Service? (October 2005) Line Vogt

448. Slovakia's introduction of a flat tax as part of wider economic reforms (October 2005) Anne-Marie Brook and Willi Leibfritz

447. The Education Challenge in Mexico: Delivering Good Quality Education to All (October 2005) Stéphanie Guichard 
446. In Search of Efficiency: Improving Health Care in Hungary (October 2005) Alessandro Goglio

445. Hungarian Innovation Policy: What's the Best Way Forward? (October 2005) Philip Hemmings

444. The Challenges of EMU Accession Faced by Catch-Up Countries: A Slovak Republic Case Study (September 2005) Anne-Marie Brook

443. Getting better value for money from Sweden's healthcare system (September 2005) David Rae

442. How to reduce sickness absences in Sweden: lessons from international experience (September 2005) David Rae

441. The Labour Market Impact of Rapid Ageing of Government Employees: Some Illustrative Scenarios (September 2005) Jens Høj and Sylvie Toly

440. The New OECD International Trade Model (August 2005) Nigel Pain, Annabelle Mourougane, Franck Sédillot and Laurence Le Fouler

439. The French Tax system: Main characteristics, recent developments and some considerations for reform (July 2005) Willi Leibfritz and Paul O'Brien

438. The Effects of EMU on Structural Reforms in Labour and Product Markets (July 2005) Romain Duval and Jørgen Elmeskov

437. Product Market Competition andEconomic Performance in New Zealand (July 2005) Annabelle Mourougane and Michael Wise

436. Getting the Most out of Public Sector Decentralisation in Spain (July 2005) Isabelle Joumard and Claude Giorno

435. Sources of Inflation Persistence in the Euro Area (July 2005) Boris Cournède, Alexandra Janovskaia, Paul van den Noord

434. Measuring Cyclically-Adjusted Budget Balances for OECD Countries (July 2005) Nathalie Girouard and Christophe André

433. Product Market Competition and Economic Performance in the United Kingdom (June 2005) Maria Maher and Michael Wise

432. The Benefits of Liberalising Product Markets and Reducing Barriers to International Trade and Investment: the Case of the United States and the European Union (June 2005)

431. Boosting Growth through Greater Competition in Denmark (May 2005) Martin Jørgensen

430. Fifteen Years of Economic Reform in Russia: What Has Been Achieved: What Remains to be Done? (May 2005) Rudiger Ahrend and William Tompson

429. Assessing the OECD Job Strategy: Past Developments and Reforms (May 2005) Nicola Brandt, Jean-Marc Burniaux and Romain Duval 